\title{
On the exponent in the von Bertalanffy growth model
}

\author{
Katharina Renner-Martin Corresp., ${ }^{1}$ ， Norbert Brunner ${ }^{1}$, Manfred Kühleitner ${ }^{1}$ ， Werner Georg Nowak ${ }^{1}$, Klaus \\ Scheicher ${ }^{1}$ \\ ${ }^{1}$ Department of Integrative Biology and Biodiversity, Institute of Mathematics, Universität für Bodenkultur Wien, Vienna, Austria \\ Corresponding Author: Katharina Renner-Martin \\ Email address: katharina.renner-martin@boku.ac.at
}

Bertalanffy proposed the differential equation $m^{\prime}(t)=p \times m(t)^{a}-q \times m(t)$ for the description of the mass growth of animals as a function $m(t)$ of time $t$. He suggested that the solution using the metabolic scaling exponent $a=2 / 3$ (von Bertalanffy growth function VBGF) would be universal for vertebrates. Several authors questioned universality, as for certain species other models would provide a better fit. This paper reconsiders this question. Based on 60 data sets from literature (37 about fish and 23 about non-fish species) it optimizes the model parameters, in particular the exponent $0 \leq a<1$, so that the model curve achieves the best fit to the data. The main observation of the paper is the large variability in the exponent, which can vary over a very large range without affecting the fit to the data significantly, when the other parameters are also optimized. The paper explains this by differences in the data quality: Variability is low for data from highly controlled experiments and high for natural data. Other deficiencies were biologically meaningless optimal parameter values or optimal parameter values attained on the boundary of the parameter region (indicating the possible need for a different model). Only 11 of the 60 data sets were free of such deficiencies and for them no universal exponent could be discerned. 
1 On the exponent in the von Bertalanffy growth model

2 Katharina Renner-Martin, Norbert Brunner, Manfred Kühleitner, Werner-Georg Nowak, and

3 Klaus Scheicher

4 Institute of Mathematics, Department of Integrative Biology and Biodiversity Research,

5 University of Natural Resources and Life Sciences, Gregor Mendel Straße 33, A-1180 Vienna, 6 Austria

7 Corresponding author:

8 Katharina Renner-Martin

9 E-mail: kathi.renner-martin@gmx.de 
On the exponent in the von Bertalanffy growth model

11

12

13

14

15

\begin{abstract}
Bertalanffy proposed the differential equation $m^{\prime}(t)=p \cdot m(t)^{a}-q \cdot m(t)$ for the description of the mass growth of animals as a function $m(t)$ of time $t$. He suggested that the solution using the metabolic scaling exponent $a=2 / 3$ (von Bertalanffy growth function VBGF) would be universal for vertebrates. Several authors questioned universality, as for certain species other models would provide a better fit. This paper reconsiders this question. Based on 60 data sets from literature ( 37 about fish and 23 about non-fish species) it optimizes the model parameters, in particular the exponent $0 \leq a<1$, so that the model curve achieves the best fit to the data. The main observation of the paper is the large variability in the exponent, which can vary over a very large range without affecting the fit to the data significantly, when the other parameters are also optimized. The paper explains this by differences in the data quality: Variability is low for data from highly controlled experiments and high for natural data. Other deficiencies were biologically meaningless optimal parameter values or optimal parameter values attained on the boundary of the parameter region (indicating the possible need for a different model). Only 11 of the 60 data sets were free of such deficiencies and for them no universal exponent could be discerned.
\end{abstract}

\title{
1. Introduction
}

Growth model: Size at age is a key metric of productivity for any animal population (MacNeil et al., 2017) and a wide range of growth models to describe the size and also the mass of animals as a function of time has been developed. Amongst applications is stock assessments in fisheries management (Juan-Jorda et al., 2015) and applications in ecology, e.g. understanding outbreak dynamics (Pratchett, 2005). Of particular interest are models based on biological principles. This paper considers a class of such models that was developed by Bertalanffy (1957), who formulated a differential equation of ontogenetic growth:

(1) $\frac{d m(t)}{d t}=p \cdot m(t)^{a}-q \cdot m(t)$

Equation (1) aims at explaining the allocation of metabolic energy between growth and sustenance of an organism, using a metabolic scaling exponent $0 \leq a<1$ : If $m=m(t)$ is body mass (weight) at age $t$, then the body utilizes resources at a metabolic rate $\left(p \cdot m^{a}\right)$ for growth, except for catabolism (energy use for the operation and maintenance of existing tissue) proportional to body weight $(q \cdot m)$. The parameters $p$ and $q$ are positive constants obtained by fitting the model curve (1) to growth data.

Is there a universal exponent? Does the modeling of the growth of different species require different metabolic scaling exponents? The null hypothesis would state that on the contrary a certain universal exponent would suffice. Several concrete values for such an exponent have been proposed in literature, resulting in a scientific controversy about the 'true' exponent (Isaac and Carbone, 2010).

Bertalanffy $(1934,1949,1957)$ suggested that $a=2 / 3$ would describe the mass growth of vertebrates; this defines the classical von Bertalanffy growth function (VBGF). Bertalanffy explained this value of the exponent by a biological reasoning: Anabolism (synthesis for growth) 
48 would be proportional to the $2 / 3^{\text {th }}$ power of body weight, as the oxygen consumption would be

49 proportional to surface $\left(2 / 3^{\text {th }}\right.$ power of volume). This value was supported e.g. by Banavar et al.

50 (2002) and White and Seymour (2003).

51 West et al. (2001) proposed an alternative value $a=3 / 4$ of the exponent, as anabolism would relate 52 to the number of capillaries, which in turn would be proportional to the $3 / 4^{\text {th }}$ power of the number 53 of cells (proportional to body mass). Actually, a metabolic exponent $a=3 / 4$ had been suggested 54 much earlier by Kleiber (1947). This value was also supported by Darveau et al. (2002) and it is 55 widely used in animal science.

56 Bertalanffy identified also species, where mass growth would be better described by an exponent $57 a=0$. Moreover, an exponent $a_{L}=0$ is widely used to describe the length growth of fish and 58 many authors reported an excellent fit also for e.g. shellfish (Koch et al., 2015). For instance, the 59 FishBase database (Frose and Pauly, 2017) presumes this model and lists growth parameters for 602320 species. In addition, a search in Google Scholar identified approximately 25,000 papers 61 related to the use of this model for fish. The use of this model in literature was also specifically 62 surveyed for elasmobranch species, showing that it was studied twice as often as any other model 63 (Smart et al. 2016).

64 More recent literature observed that no single exponent may be exactly correct. As Killen et al. 65 (2010) and White (2010) observed, for different species there were different optimal exponents $66 a_{\text {opt }}$. Also for the same species data sets differing in environmental factors (e.g. food composition, 67 temperature) supported different exponents; c.f. Kimura (2008), Porch (2002), Quince et al. 68 (2008), Stewart et al. (2013), or Yamamoto and Kao (2012).

There were also suggestions that the very problem of determining an optimal exponent may be ill-posed. For, as Shi et al. (2015) observed, for some data sets a near-optimal fit could be achieved by a wide range of exponents. As a consequence, data fitting using nonlinear regression by means of the method of least squares may be impeded by numerical instability.

Problem of the paper: The present paper develops an approach to identify best fitting exponents for model (1) despite numerical instability and applies this to explore the variability of the exponent. To this end, the growth model (1) was applied to 60 data sets and best fit exponents together with suitable best fit parameters were determined.

77

78

79

80

81

82
In order to compare the goodness of fit across different data sets, the paper applies Akaike's information criterion: Given the optimal exponent $a_{\text {opt }}$, computed for a certain data set, and a hypothesized exponent $a$ (e.g. a universal value for the exponent) the Akaike weight prob $(a)$ is the probability that the model (1) using the hypothesized exponent $a$ is true, when compared with the optimal exponent $a_{\text {opt }}$. Thereby, given a data set, the exponent $a$ is refuted for this data set, if in comparison to $a_{\text {opt }}$ its Akaike weight is below 2.5\%. Variability of the exponent is measured by the length of the interval of not-refuted exponents.

\section{Materials and methods}

Choice of the growth model: Model (1) is believed to have a biological meaning (see the introduction). This was the main reason, why the authors decided to study this model in more detail. This distinguishes model (1) from simpler models recommended in literature for data interpolation, such as power-laws between size and age (Katsanevakis and Maravelias, 2008). 
89

90

91

92

93

94

95

96

97

98

99

100

101

102

103

$$
\text { (2) } \frac{m(t)}{m_{\max }}=\sqrt[1-a]{1-\left(1-\left(\frac{m_{0}}{m_{\max }}\right)^{1-a}\right) \cdot e^{-q \cdot(1-a) \cdot t}}
$$

104

105

106

107

108

109

110

111

112

113

114

115

116

117

118

119

120

121

122

123

124

125

\section{PLEASE INSERT FIGURE 1} be applied for data fitting: VBGF with $a=2 / 3$.

Another reason to study model (1) was the boundedness of the model function and its sigmoid shape, if $a, p, q>0$ : The rate of mass growth increases, as size increases, until it reaches a maximal value and then decreases towards zero as mass approaches the asymptotic weight limit $m_{\max }$ (mature body mass). This is a unimodal curve, peaking above the weight at the inflection point. To demonstrate the plausibility of this model, Figure 1 compares this theoretical pattern of the growth rate, i.e. the right hand side of equation (1), with observed growth rates from data.

As follows from this shape of the model curve for $a, p, q>0, m_{\max }=(p / q)^{1 /(1-a)}$ is the positive zero of the right hand side of equation (1); the rate of growth vanishes for $m=m_{\max }$. The inflection point is assumed, when body mass reaches the value $m_{\text {infl }}=a^{1 /(1-a)} \cdot m_{\max }$; the derivative of the right hand side of equation (1) vanishes for $m=m_{\text {infl }}$. The fraction $m_{\text {infl }} / m_{\max }$ varies between just above $0 \%$ and just below $1 / e=37 \%$, the limits of $a^{1 /(1-a)}$ for $a \rightarrow 0$ and for $a \rightarrow 1$, respectively.

An additional reason for the selection of model (1) was the availability of an explicit solution (2) of equation (1) in terms of elementary functions (Bertalanffy, 1957), whence spreadsheets could

Formula (2) explains growth in terms of four parameters: the exponent $a$, the growth coefficient $k$ $=q \cdot(1-a)$, the initial value (neonate weight) $m_{0}=m(0)$, and $m_{\max }$. (The dimensions are mass in $\mathrm{g}$ or $\mathrm{kg}$ for $m, m_{0}$ and $m_{\max }$, time in $\mathrm{d}$, months or years for $t, 1 /$ time for $q$ and dimensionless for $a$.) In literature there are different parametrizations and the present one follows a recommendation of Cailliet et al. (2006). Knowing $a$ and $q$ allows to compute $m_{\max }$ and $p$ from each other (using the formula for $\left.m_{\max }\right): p=q \cdot m_{\max }{ }^{1-a}$. Several papers use a time shift $t_{0}$ to eliminate the multiplicative constant of formula (2), but $t_{0}$ might not have a biological meaning (Schnute and Fournier, 1980).

Formula (2) is also valid for an exponent $a=0$, where it is the model of bounded exponential growth. There, the difference $m_{\max }-m(t)$ between mature body mass $m_{\max }$ and current weight follows the model of exponential decay and the model curve is not sigmoid. As Bertalanffy (1957) observed, the model for length growth using the exponent $a_{L}=0$ is equivalent to VBGF for mass growth with a metabolic scaling exponent $a=2 / 3$. Therefore, in fishery literature both models are referred to as VBGF. However, for this paper, VBGF always means $a=2 / 3$. The equivalence between the models was meant in the following sense: If mass growth is described by the VBGF with $a=2 / 3$ and if mass is assumed to be proportional to the third power of length, then the growth of length is modeled by bounded exponential growth $a_{L}=0$. And conversely, if length increases according to bounded exponential growth, $a_{L}=0$, then mass growth follows

The authors acknowledge that there is room for alternative models and that certain data sets may not be appropriate for further analysis by model (1). In particular, model (1) may be generalized using more parameters. For instance, in (1) the term $q \cdot m$ for catabolism may be replaced by a more general term $q \cdot m^{b}$ (Pütter, 1920). This more general equation includes certain well-known 
126 models, e.g. for $a=1$ a model due to Richards (1959) and for $b=2$ generalizations of the logistic 127 growth function of Verhulst (1838). However, the equation for the generalized model is no longer 128 solvable using elementary functions (Ohnishi et al., 2014). Such more complex models may be 129 analyzed using numerical solutions of differential equations (e.g. Leader, 2004), but then 130 numerical errors would require further analysis. Further, while for such models with more free 131 parameters the fit of the model curve to the data may be better, overfitting may result in 132 unrealistic parameter values.

133 Summarizing, with four parameters model (1) appeared to be flexible enough to represent growth 134 curves of different sigmoid shapes and to allow for handling numerical instability, when 135 analyzing the problem of the variability of the parameters.

136 Data: Tables 1 and 2 summarize the used data and the primary sources. The main secondary 137 sources were Parks (1982), Ogle (2017) and the supporting information of West et al. (2001). The 138 authors supplemented them by data from other literature sources and from personal 139 communications. Data in diagrams were retrieved by means of digitalization (Digitize-It of 140 Bormisoft $^{\circledR}$ ). Obvious outliers were removed; this applied to data set \#10 (Bull Trout).

141 Only data sets with $N=6$ or more points of time were considered. Amongst data sets removed for 142 this reason were fish data about Channel Darter from Reid (2004) and Creek Chub from Quist et 143 al. (2012). In average, data sets had 23 points of time (maximum 110).

144 With respect to data collection, the paper distinguishes natural and controlled data. Most fish data were natural data. For non-fish only controlled data were collected and natural data were

147 Muntjak Deer from Pei, 1996). Thereby, controlled data were based on repeated measurements of 148 the same animals (pets, aquarium fish, farmed animals, laboratory animals). The age of the 149 animals was known, the food intake was controlled and they could easily be grouped by objective 150 factors (e.g. sex, strain). Natural data came from hunting, fishing or capturing of wildlife, 151 whereby in general animal age was estimated (e.g. otolith analysis). Thereby, e.g. spawning time 152 caused additional age uncertainties for fish (Datta and Blanchard, 2016).

153 The tables inform also about the number of data points for each data set, counting the points of 154 time. At each point of time the weights from one to several thousand animals (e.g. data set \#50)

155 were averaged. Specifically, data sets \#47 and 55 were growth data from repeated measurements 156 of a single animal. All other controlled data were average values of repeated measurements of 157 groups of animals (group size in general 15-30 animals.) The natural data averaged over non158 repeated measurements of different animals.

\section{PLEASE INSERT TABLE 1}

160 The authors considered only age-mass or age-length data; the latter only for fish. For most fish 161 (see Table 1) sources provided (average) lengths of different fish of approximately the same age. 162 In order to use data of the same format, length data were transformed into mean-weight-at-time 163 data. Empirical evidence for fish suggested that mass may be related to length by an allometric 164 power relation $m(t)=c \cdot l(t)^{p}$ with $2.5<p<3.5$ and some constant $c$ (Pauly, 1979; Anderson and 165 Neumann, 1996). There were slight differences in the parameters $c$ and $p$, depending on which 166 concept of length was used (Holden and Raid, 1974: standard length, fork length, total length). 
167 For simplicity, the paper approximated mass by the third power of length. This convention was in

168 line with Bertalanffy $(1934,1957)$ and it avoided mixing up information from different sources

169 about time-length and length-mass relations.

170 PLEASE INSERT TABLE 2

171 PLEASE INSERT FIGURE 2

172 The search for data aimed at capturing the full growth phase, from an early point in life (birth) till

173 the end of growth (e.g. sexual maturation). For otherwise (Figure 2), the modeling of a growth

174 curve would depend on extrapolation. In particular, as Knight (1968) suggested, if $m_{\max }$ was

175 excessive compared to the maximal observed weight $m_{o b s}$, then the model curve would not be

176 supported by the data. Therefore, this paper considered $m_{\max }$ as excessive, if $m_{\max } \geq 1.5 \cdot m_{o b s}$, and

177 for sigmoid model functions, if $m_{\text {infl }} \geq m_{\text {obs }}$ (Figure $2 \mathrm{~b}$ ). The latter condition indicates that the

178 weight $m_{\text {infl }}$ at the inflection point exceeds the maximal observed weight, whence the inflection

179 point of the best fitting model curve is not visible in the data. (For good approximations at least

180 three observations should be located before and after the inflection point of the model curve,

181 respectively.). However, the authors did not discard of such data. For first, ideally a good growth

182 model should predict the mature body mass at a juvenile age, already. And second, $m_{\max }$ did not

183 relate alone to the data, but to data fitting. The paper therefore retained such data and marked

184 those with an excessive $m_{\max }$. An exception were the Freshwater Drum data from Bur (1984),

185 removed due to an infinite asymptotic weight.

186 Statistical methods and data fitting: Generally, computations were done in Microsoft ${ }^{\circledR}$ EXCEL. 187 Optimization used its SOLVER Add-In, which implemented an iterative optimization method

188 (Newton's method). Casella and Berger (2001) was used as a standard reference for statistics and 189 XL-Stat of Addinsoft ${ }^{\circledR}$ was used for statistical computations.

190 Nonparametric Mann-Whitney test was used for the comparison of location parameters. (For 191 example, mean values of optimal exponents were compared for different groups of data sets.) 192 Anderson-Darling test was used to assess the good fit of a normal distribution. The Fisher exact 193 test was used for testing the significance of contingencies and the $t$-test was used to test the 194 significance of correlations. These computations used XL-Stat.

195 For confidence intervals, Clopper-Pearson confidence limits were used, as these are conservative 196 (higher confidence than stated) and suitable for small samples. Given a sample of size $M$ (the 197 number of data sets) and amongst them $m$ ones with a specific property (the number of data sets 198 not rejecting a certain exponent), then using the beta distribution and EXCEL notation, the one199 sided lower 90\%-confidence limit and the upper 90\%-confidence limit for the frequency of this 200 property in the population were $1-\operatorname{BETA} \operatorname{INV}(0.9 ; M-m+1 ; m)$ and $\operatorname{BETA.INV}(0.9 ; m+1 ; M-m)$. 201 Excel notation is used as there is no standard mathematical notation for the involved functions.

202 For data fitting, the paper used nonlinear regression by means of the method of least squares. As 203 Figure 3 illustrates, for certain data sets it was meaningful to identify optimal exponents by this 204 method, as the resulting fit to the data of the model curves (1) was evidently different for 205 different exponents. (Thereby, except for the exponent, all other model parameters were selected 206 to ensure a best fit.) This approach assumed age was controlled and weight observations came 207 from a random sample of animals with a given age. Implicitly, the method of least squares is a 
208 maximum likelihood estimate assuming normally distributed deviations of the data from the 209 model curve (residuals).

210 PLEASE INSERT FIGURE 3

211 Alternative regression models: As there is a large body of nonlinear regression literature, a few 212 explanations are added to justify the above choice of methods. For instance, in fisheries literature 213 it has been recommended to assume that weight was controlled and age observations came from a 214 random sample of animals with a given weight (Sparre and Venema, 1988; Piner et al., 2012). For 215 the paper, this approach was rejected, as for the present data, all non-fish data were controlled for

216 age and for most non-fish data there was no control. However, as explained below, the alternative 217 approach was used for the numerical computations to obtain a first approximation of the best fit 218 parameters.

219 There are alternative heteroscedastic growth models assuming a larger variance for higher 220 weights. (For example, for lognormally distributed weights the standard deviation is proportional 221 to the expected weight.) An increase in variance may also be caused by the availability of fewer 222 data for older animals. (This relates to the dependency of the variance of the mean value on 223 sample size.) However, owing to relatively small sample sizes (counting the number of different 224 points of time) distribution fit tests did not refute the assumption of normally distributed residuals 225 for the present data sets. Therefore, the paper used the simpler least squares method.

226 Literature in the context of feeding experiments applies also improvements of regression models, 227 such as mixed-effect models (e.g. Strathe et al., 2010). However, as the purpose of such models 228 would be the identification of explanatory factors for growth (e.g. gender), such models require 229 highly controlled experiments, distinguishing the relevant factors in the data. For most of the 230 present data such information was not available. (For instance, many data sets did average over 231 male and female fish.) Therefore, the present paper did not study such more complex models.

232 In a different direction the model fit could be simplified by using literature values for certain 233 parameters. For instance, for fishes the mass at age $0\left(m_{0}\right)$ is largely similar (Andersen, 1969), 234 whence a literature value for $m_{0}$ could be used instead of optimizing this parameter. However, by 235 this approach the weight at $t=0$ would be exceptional in comparison to other data points, which 236 it is not, whence also in fishery literature the parameter $m_{0}$ is usually optimized. Further, for non237 fish species the neonate weight is more variable and the authors did not wish to treat data fitting 238 differently for different species.

239 Numerical approach towards data fitting: For most data sets a straightforward approach 240 towards data fitting failed due to numerical instability. (Data fitting means searching for values $a$, $241 m_{0}, m_{\max }$, and $q$, where the sum of squared residuals is minimal.) The authors therefore did 242 optimization in two steps:

243 In the first step, given an exponent $0 \leq a<1$, optimal parameter values $m_{0}, m_{\max }$, and $q>0$ for 244 model (2) were sought to minimize the sum of squared residuals between the data points and the 245 model function; the squared residual for the $n^{\text {th }}$ data point $\left(t_{n}, m_{n}\right)$ is $\left(m_{n}-m\left(t_{n}\right)\right)^{2}$ and $\operatorname{SSR}=\operatorname{SSR}(a)$ 246 is the sum of these residuals.

247 In the second step, the paper sought to obtain an optimal exponent, where $S S R=S S R(a)$ was 248 minimal; the desired accuracy for the exponent was 0.01 . Therefore, using a macro the 
249 optimization was repeated for each exponent $a=0,0.01,0.02, \ldots$, and 0.99 , resulting in 100

250 models for each dataset. The resulting minimal values of $\operatorname{SSR}(a)$ were tabulated. Summarizing,

251 this defined an optimal exponent $a_{o p t}<1$ and optimal parameter values $m_{0}, m_{\max }$, and $q$ for this

252 exponent.

253 In view of numerical instability, the convergence of the first step of optimization (using the

254 SOLVER) required good initial estimates of the optimum parameters. These were computed by

255 adapting a graphical method (Figure 4), the Bertalanffy-Beverton plot (Bertalanffy, 1934). It was

256 based on two ideas: Fitting the inverse of function (2) to the weight-time data (rather than fitting

257 to time-weight data) and finding a transformation of the weight-time data which allows to use a

258 linear regression for this exercise.

259 Summarizing, this method aims at computing an optimal fit of the weight-time data to the inverse

260 function of (2). It is described by equation (3) for $t=t(m)$; $\ln$ is the natural logarithm function:

261

(3) $t=\frac{f\left(m_{0}\right)-f(m)}{q}$ where $f(x)=\frac{\ln \left(1-\left(x / m_{\max }\right)^{1-a}\right)}{1-a}$ for $x<m_{\max }$

262 Collecting terms not depending on $m$ simplified this to equation (4):

263

$$
t=A+B \cdot f(m) \quad \text { with } A=f\left(m_{0}\right) / q, B=-1 / q
$$

264 The Bertalanffy-Beverton plot (Figure 4) was motivated by equation (4): Plotting, for all data

265 points, time $t$ over transformed mass $f(m)$ should result in approximately a straight line.

266 Therefore, $A, B$ in formula (4) are the coefficients of a linear regression line $t=A+B \cdot u$ that is

267 fitted to transformed data $\left(u_{n}, t_{n}\right)=\left(f\left(m_{n}\right), t_{n}\right)$, using the function $f$ of equation (3). In EXCEL, $A$

268 and $B$ were computed with the LINEST function.

\section{PLEASE INSERT FIGURE 4}

270 However, by equation (3), this transformation depends on assuming, in addition to the given exponent $a$, a value for the (true) asymptotic weight limit $m_{\max }$. As $m_{\max }$ was not known, the

272

273 goodness of fit of the regression line was evaluated for different values of $m_{\max }$, using the sum of

274 squared residuals $S S R_{i n v}\left(m_{\max }\right)$ for the transformed data. This defined a function in $m_{\max }$. (In EXCEL, it was again computed by the LINEST function.) It was assumed that this sum $\operatorname{SSR}_{\text {inv }}\left(m_{\max }\right)$ was minimal for the true $m_{\max }$.

The search for $m_{\max }$ with a minimal sum $S S R_{\text {inv }}\left(m_{\max }\right)$ caused no numeric problems: As illustrated by Figure 5, for all data the function $S S R_{\text {inv }}\left(m_{\max }\right)$ decreased rapidly for $m_{\max }$ near the maximum $m_{o b s}$ of the observed data (observed maximum) and it was flat for larger values of $m_{\max }$. The SOLVER Add-In minimized this function iteratively (using as a starting value $1.01 \cdot m_{\text {obs }}$ ) under the additional constraints $m_{\max }>m_{o b s}$, as otherwise $f(m)$ would not be defined for the larger data, and $m_{\max }<100 \cdot m_{o b s}$, as in view of the flat curve larger values of $m_{\max }$ did not substantially reduce $S S R_{\text {inv }}$. (For the purpose of optimization it did not matter that an excessive $m_{\max }$ was not always empirically meaningful.) As the optimization used exact formulae for $A, B$ (LINEST function) and as it was done in one dimension (seeking $m_{\max }$ with minimal $S S R_{i n v}$ ), it could be performed fast and with high precision. 
286

287

288

289

290

291

292

293

294

295

296

297

298

299

300

301

302

303

304

305

306

307

308

309

310

311

312

313

314

315

316

317

318

319

320

Using this preliminary optimization, the following initial estimates for the fit of model (2) to the data were used: the given exponent $a$, the above optimized $m_{\max }, q=-1 / B$, and for $m_{0}$ the least observed weight $m_{\min }$.

\section{PLEASE INSERT FIGURE 5}

These values $m_{0}, m_{\max }$, and $q$ were used as starting values for the first optimization step, the iterative optimization of $S S R=\operatorname{SSR}(a)$, given the exponent $a$. For all data sets, the SOLVER converged. In order to hinder parameter values from moving from the reasonable starting values into a region of divergence, the above constraints $m_{o b s}<m_{\max }<100 \cdot m_{o b s}$ were retained and $m_{0}>$ $m_{\text {min }} / 100$ was added.

As for a computationally simpler method of obtaining initial estimates for the best fit parameters, there is a large body of literature using the Walford plot for data fitting (e.g. Espino-Barr et al., 2015), which was explained in Figure 1. However, that method did not always provide good initial estimates.

Model comparison: In order to compare the goodness of fit, for each data set the 100 models corresponding to different exponents $a<1$ were assessed by means of the Akaike information criterion (Akaike, 1974; Burnham and Anderson, 2002; Motulsky and Christopoulos, 2003), using an index $A I C_{c}$ for small sample sizes. It was computed from $\operatorname{SSR}(a)=$ the sum of squared residuals, $N=$ number of data points, and $K=4=$ number of optimized parameters (namely $m_{0}$, $m_{\max }, q$ and implicitly $S S R$ ). The number of data points essentially counted, for how many points of time (ages) there were data. (If there were several observations for the same age, as e.g. for reported average values for groups of animals, then this was counted as one data point.)

$$
A I C(a)=N \ln \left(\frac{\operatorname{SSR}(a)}{N}\right)+2 \cdot K+\frac{K \cdot(K+1)}{N-K-1}
$$

(6) $\operatorname{prob}(a)=\frac{e^{-\Delta / 2}}{1+e^{-\Delta / 2}}$, where $\Delta=A I C(a)-A I C\left(a_{o p t}\right)>0$

Formula (6) gives the probability prob (Akaike weight) that the model with exponent $a$ was true, when compared with the better fitting model with exponent $a_{\text {opt }}$, assuming that either $a$ or $a_{\text {opt }}$ would be the true exponent. Assuming that one of the two exponents $a$ or $a_{\text {opt }}$ is true, then $\operatorname{prob}(a)$ $+\operatorname{prob}\left(a_{o p t}\right)=100 \%$. If the better fitting model is more likely to be true, $\operatorname{prob}(a) \leq \operatorname{prob}\left(a_{o p t}\right)$. It follows that $\operatorname{prob}(a) \leq 50 \%$ and $\operatorname{prob}\left(a_{\text {opt }}\right)=50 \%$.

For the present paper, an exponent $a$ is refuted (for a data set), if in comparison to $a_{o p t}$ its Akaike weight is below $2.5 \%$. (Thus, 'below $2.5 \%$ ' defines the $5 \%$ of the index values with the worst fit.) The paper uses the Akaike weight for this definition, as other measures for the goodness of fit (e.g. $S S R$ ) make sense only with respect to one given data set, while the present paper seeks a definition applicable across different data sets. Further, this notion of refutation uses the Akaike weight merely as an index for the goodness of fit, whence a notion of truth is not required. In particular, the paper makes no assumption, whether one of the exponents $a$ or $a_{\text {opt }}$ is true, as this is not needed for a refutation owing to a poor fit: If a model (defined from an exponent $a$ ) is refuted, 
321 as it fares poorly amongst its 'peers', it is sensible to refute it also for any larger group of models.

322 Further, if model (1) were false, then the refutation of such an exponent $a$ would be sensible

323 anyway.

\section{PLEASE INSERT FIGURE 6}

325 The Akaike weight was used to quantify the variability of the exponent, figuring out over which 326 range of exponents the best fit to the data did not change significantly. However, as this weight

327 was sensitive to outliers, in a preparatory step outliers had to be removed; see Figure 6 . The curve $328 \operatorname{prob}(a)$ had its peak at $a_{\text {opt }}$ and it was increasing/decreasing for lower/higher values of $a$.

329 Therefore, the non-refuted exponents formed an interval.

330 FNR is the fraction of non-refuted exponents amongst the 100 considered exponents $(a=0,0.1$, 331 ..., 0.99). It measures, how strong the optimal exponent is determined by the data; the lower the 332 FNR the less uncertainty remains about the value of the exponent $a$. FNR was computed as the 333 difference between High and Low of Table 3 plus 0.01 (as $a_{\text {opt }}$ is not refuted), whereby High and 334 Low were the highest and lowest non-refuted exponents.

\section{3. Results}

336 Table 3 summarizes the fit of model (1) to 60 data sets. There occurred three issues.

337 First, there was a high variability in the exponent $a$, which for 18 data sets could take any value 338 (between 0 and 0.99) without affecting the fit to the data significantly (when the other model 339 parameters were optimized); FNR $=1$ for these data sets. Consequently, it could not be assured 340 that a biologically correct exponent could be identified from data fitting.

341 Second, there were problems with unrealistic parameter values, specifically for the estimated 342 mature body mass $m_{\max }$. For 13 data sets, it exceeded the maximally observed weight by $50 \%$

$343\left(m_{\max } / m_{o b s} \geq 1.5\right)$, whence boundedness was not evident from the data, and for 7 data sets with 344 sigmoid model curves $\left(a_{\text {opt }}>0\right)$ the weight at the inflection point exceeded the maximally 345 observed weight $\left(m_{i n f l} \geq m_{o b s}\right)$, whence the sigmoid shape of the model curve was not discernible 346 from the data. For one data set (\#50, domestic pig), the excessive $m_{\max }$ could be explained in part 347 from data collection, as it ended long before sexual maturity had been reached.

\section{PLEASE INSERT TABLE 3}

349 Third, there was a concentration of the optimal parameters on the boundary of the parameter 350 space. (If maximum likelihood parameters assume values on the boundary of the parameter 351 space, then the normal distribution of the optimal parameters is no longer assured.) For 15 data 352 sets $m_{\max }=m_{o b s}$ assumed the lower bound for optimization. Moreover, for 24 data sets, the 353 exponent was optimal for the largest value $a=0.99$; for 5 data sets, the exponent was optimal for 354 the lowest value $a=0$ (not sigmoid). The tendency towards higher exponents persisted, if the 355 variability was taken into account (Figure 7): For 55 data sets the interval of non-refutation 356 reached the upper bound 'High' $=0.99$. Further, for any $a \leq 0.01$, at least $50 \%$ of data sets would 357 reject this low exponent, while for any $a \geq 0.89$, at least $80 \%$ of data sets would not reject this 358 high exponent. (For each statement 95\% confidence was confirmed, assuming data sets selected 359 at random by the same strategy, as for this paper.) 
361 Summarizing, model (1) may be suitable to describe the growth of certain species, but for 49

$362(82 \%)$ of the 60 data sets (95\% confidence: at least $72 \%$ of data sets) there were issues for

363 optimization with unrealistic model parameters, with parameters on the boundary of the

364 parameter space, or with elusive parameters that due to a high variability could not be determined

365 accurately from the data. This indicated that for a substantial fraction of species a more general or

366 a completely different class of models might be needed to describe growth more realistically.

367 In particular, the data did not support the claims from literature about the existence of a universal 368 exponent for model (1) that would suffice to describe the growth of a large taxonomic group of 369 animals. On the contrary, also for the 11 data sets not showing the above issues (\#1, 2, 4, 10, 22, $37025,33,44,47,52,56)$, the optimal exponent $a_{\text {opt }}$ varied widely and its mean value did not differ

371 significantly between these 11 data sets and the 49 problematic ones (Mann-Whitney test, $p$-value 372 20.3\%). Further, the data did not support the hypothesis that for each species there would be 373 optimal exponents to describe its growth by model (1). For, the best fitting exponents could differ 374 widely for female and male animals of the same species, as demonstrated for data sets \#18-19 375 (female and male Lake Trout) with optimal exponents 0.69 and 0.28 , respectively. Further, where 376 e.g. fish of the same species came from different locations (different water temperatures for the 377 Lake Trout data \#18-19 and \#27-28), a different pattern of growth was expected for biological 378 reasons.

\section{Discussion: explaining variability}

The observed issues, in particular the high variability of the exponent, may indicate that data fitting optimized too many parameters. However, this paper proposes an alternative explanation, namely differences in data quality. For, data for non-fish in general came from highly controlled experiments, while data for fish in general were natural data.

This claim is supported by the highly significant dependency of variability on whether the data were for fish or not: 17 of the 18 species with FNR = 1 were fish. Further, with $99.99 \%$ significance (Mann-Whitney test: $p$-value below $0.01 \%$ ) the average FNR for fish $(0.8)$ was stochastically larger than the average FNR for non-fish (0.38), even though there were also fish with small FNR (e.g. FNR =0.1 for Artic Cod \#3).

Ignoring this variability could generate artefacts. For instance, with 95\% significance (MannWhitney test, $p$-value $4.7 \%$ ) the mean value of the optimal exponents for fish (0.61) was stochastically lower than the mean value for non-fish (0.79). However, the reason for this could be variability, as with $99.99 \%$ significance the optimal exponents were negatively correlated with FNR ( $t$-test: $p$-value below $0.01 \%$ ); i.e. lower optimal exponents for fish were related to a higher FNR (because 'Low' became smaller). By contrast, there were no 95\% significant differences between fish and non-fish for the fractions $m_{\max } / m_{o b s}$ and $m_{\text {infl }} / m_{o b s}$.

The following discussion aims at discerning characteristic features of natural data, which did/did not affect variability.

\section{PLEASE INSERT FIGURE 8}

\section{PLEASE INSERT FIGURE 9}


400

401

402

403

404

405

406

407

408

409

410

411

412

413

414

415

416

417

418

419

420

421

422

423

424

425

426

427

428

429

430

431

432

433

434

435

436

437

438

439

440
An obvious difference between fish and non-fish data was the transformation of length to weight, which was needed for most fish. This paper used a power-law transformation $m(t)=l(t)^{p}$ with $p=$ 3 for fish. As Figure 8 illustrates, this convention could have affected refutations, but it could not explain a systematic bias towards easier or more difficult refutations. (In the figure, higher/lower values of $p$ make refutations easier/more difficult. However, for some data, the 'true' $p$ was below 3 and for others it was above 3.)

Another difference between data sets was insufficient stratification for fish: For non-fish species the data for females and males of the same species were collected separately, this was not the case for all fish. In case that these groups had a different growth pattern (different optimal exponents), as for Figure 9, the combination of data could result higher FNR. (Intuitively, combined data have higher residuals, making refutations more difficult.) Similar effects could have been generated from the combination of data from different locations or from data about migrant animals, collected at the same location but not taking into account the different origin of the animals.

However, in the authors' view, the main difference seems to have been whether data were comprised of repeated measurements of the same animals (controlled data) or of single measurements of randomly chosen animals (natural data). For, the three discarded natural data sets for non-fish species showed a high variability in the exponent, as did the fish data, and the three fish data sets from controlled experiments showed a rather lower variability. (More data sets would be needed to support this view by statistical reasoning.)

The authors developed the following strategy to identify data sets, where model (1) could be expected to provide an adequate fit: Data were removed, if FNR $=1$ (maximal variability), $m_{\text {max }} / m_{\text {obs }} \geq 1.5, m_{\text {inff }} / m_{\text {obs }} \geq 1$ (unrealistic parameter values), $a_{o p t}=0, a_{o p t}=0.99$, or $m_{\text {max }} / m_{\text {obs }}=1$ (parameters on the boundary). There remained 11 data sets. For them here was no significant contingency between fish and non-fish data. (Fisher exact test resulted in the $p$-value $100 \%$, testing the contingency table comprised of 7 selected and 30 non selected fish and of 4 selected and 19 non selected non-fish.) Thus, this strategy appeared to be successful in eliminating the differences between natural and controlled data, as far as data fitting was concerned. However, also for this smaller sample of data sets with apparently unproblematic data fitting there did not emerge a candidate for a universal exponent; the exponent $\left(a_{o p t}\right)$ took values between 0.14 and 0.94 .

\section{Conclusion}

The paper argued that the question, whether there exists a universal metabolic scaling exponent for the generalized von Bertalanffy model (1) may be ill-posed, as the biological meaning of the model exponent, and the variation in this exponent, might not be clear. To this end it computed optimal exponents from a sample of 60 data sets about the growth of animals.

A closer look at data-fitting revealed serious deficiencies. There was uncertainty about the optimal exponent (variability), there were unrealistic parameter values (excessive estimates for the mature body weight) and parameters tended to assume values on the boundary of the parameter space (indication for the need of a completely different model). With respect to variability, for a large range of exponents the best fitting model curves (optimizing the other 
441 parameters) did not differ significantly in their fit to the data. (Intuitively, plots did not show

442 noticeable deviations of the model curves with these exponents from each other.) Thereby, the

443 variability of the exponent could be related to the type of data, with natural data causing higher

444 variability than controlled data. Thereby for fish in general only natural data were available.

445 Ignoring these deficiencies could result in biologically unfounded statements, such as observing

446 stochastically lower exponents for fish than for non-fish species.

447 However, also for data sets selected for not showing the above mentioned deficiencies, the

448 optimal exponents computed from the data differed widely from the values proposed in literature

449 on the basis of biological reasoning (e.g. $a=2 / 3$ or $a=3 / 4$ ). In view of this discrepancy data

450 fitting did not support any of the biological explanations of the exponents.

451 Interpreting variability positively, if the model is merely intended to summarize information from

452 (mass) growth data by means of a few parameters, then for data sets with large variability of the

453 exponent almost any exponent may be adequate (if it is close to 1: Figure 7). Thus, in hindsight,

454 also the use of VBGF to summarize fish data (e.g. FishBase) appears to be justified, unless the

455 biological meaning of the model parameters is overstressed.

\section{$456 \quad$ Acknowledgements}

457 The authors appreciate the insightful reviewers' comments that substantially improved the paper.

458 The paper is part of the first author's doctoral thesis.

$459 \quad$ References

460 Abad, N. (1982). Ecologie et dynamique des populations de truites communes (S. trutta fario)

461 dans le bassin du Tarn. Doctoral Thesis at National Polytechnic Institute, Toulouse, France.

462 Akaike, H. (1974). A New Look at the Statistical Model Identification. IEEE Trans. Automatic

463 Control, 19, 716-723.

464 Andersen, H.T. (1969). Biology of Marine Animals. Academic Press, New York, USA.

465 Anderson, R.O.; Neumann, R.M. (1996). Length, Weight, and Associated Structural Indices, in:

466 Murphy, B.E.; Willis, D.W. (Editors). Fisheries Techniques, American Fisheries Society, pp. 447467481.

468 Araujo, J.N.; Martins, A.S. (2007). Age, growth and mortality of white grunt (Haemulon

469 plumierii) from the central coast of Brazil. Scientia Marina, 71, 793-800.

470 Bailey, M.M. (1963). Age, growth, and maturity of round-whitefish of the Apostle Islands and

471 Isle Royale regions, Lake Superior. Fishery Bulletin, 63, 63-75.

472 Banavar, J.R.; Damuth, J.; Maritan, A.; Rinaldo, A. (2002). Ontogenetic growth. Modelling

473 universality and scaling, Nature, 420, 626.

474 Bertalanffy, L.v. (1934). Untersuchungen über die Gesetzlichkeit des Wachstums. I. Allgemeine

475 Grundlagen der Theorie; mathematische und physiologische Gesetzlichkeiten des Wachstums bei

476 Wassertieren. Archiv für Entwicklungsmechanik, 131, 613-652.

477 Bertalanffy, L.v. (1949). Problems of organic growth. Nature. 163, 156-158. 
478 Bertalanffy, L.v. (1957). Quantitative laws in metabolism and growth. Quarterly Reviews of 479 Biology, 32, 217-231.

480 Brody, S. (1945). Bioenergetics and Growth. Reinhold Publishing Corporation, New York.

481 Brown, D.; Rothery, P. (1993). Models in Biology. John Wiley and Sons, New York

482 Bur, M.T. (1984). Growth, reproduction, mortality, distribution, and biomass of freshwater drum 483 in Lake Erie. Journal of Great Lakes Research, 10, 48-58.

484 Burden, R.L.; Faires, J.D. (1993). Numerical Analysis, PWS Publishing Co. Boston, MA.

485 Burnham, K.P.; Anderson, D.R. (2002). Model Selection and Multi-Model Inference: A Practical 486 Information-Theoretic Approach. Springer, Berlin.

487 Cailliet, G.M.; Smith, W.D.; Mollet, H.F.; Goldman, K.J. (2006). Age and growth studies of 488 chondrichthyan fishes: The need for consistency in terminology, verification, validation, and 489 growth function fitting. Environmental Biology of Fish, 77, 211-228.

490 Casella, G.; Berger, R.L. (2001). Statistical Inference. Thomson Learning, Stamford.

491 Cubillos, L.A.; Arcosa, D.F.; Bucareya, D.A.; Canalesa, M.T. (2001). Seasonal growth of small 492 pelagic fish off Talcahuano, Chile: a consequence of their reproductive strategy to seasonal 493 upwelling? Aquatic Living Resources, 14, 115-124.

494 Darveau, C.A.; Suarez, R.K.; Andrews, R.D.; Hochachka, P.W. (2002). Allometric cascade as a 495 unifying principle of body mass effects on metabolism. Nature, 417, 166-170.

496 Datta, S.; Blanchard, J.L. (2016). The effects of seasonal processes on size spectrum dynamics. 497 Canadian J. Fisheries \& Aquatic Sciences, 73, 598-610.

498 Espino-Barr, E.; Gallardo-Cabello, M.; Garcia-Boa, A.; Puente-Gómez, M. (2015). Growth 499 analysis of Mugil cephalus (percoidei: mugilidae) in Mexican Central Pacific. Global J. Fisheries $500 \&$ Aquaculture, 3, 238-246.

501 Forsyth, D.J. (1976). A field study of growth and development of nestling masked shrews (Sorex 502 cinereus). Journal of Mammalogy, 57, 708-721.

503 Froese, R.; Pauly, D. (2017). FishBase data base: www.fishbase.org, last accessed in August 5042017.

505 Gomez-Requeni, P.; Conceicao, L.E.C.; Olderbakk-Jordal. A.E.; Rønnestad, I. (2010). A 506 reference growth curve for nutritional experiments in zebrafish (Danio rerio) and changes in 507 whole body proteome during development. Fish Physiol. Biochemistry, 36, 1199-1215.

508 Grabowski, T.B.; Young, S.P.; Isely, J.J.; Ely, P.C. (2012). Age, growth, and reproductive biology 509 of three catostomids from the Apalachicola River, Florida. J. Fish \& Wildlife Management, 3, 510 223-237.

511 Grossman, M. (1969). A genetic and biometric study of growth in chickens. Doctoral Thesis, 512 Purdue Univ., West Lafayette, USA.

513 Holden, M.J.; Raitt, D.F.S. (1974): Manual of fishery science, II. Methods of resource 514 investigations and their application. FAO Fisheries and Aquaculture Technical Paper Series, FAO, 515 Rome, Italy. 
516 House, R.; Wells, L. (1973). Age, growth, spawning season, and fecundity of the trout-perch

517 (Percopsis omsicomaycus) in southeastern Lake Michigan. J. Fisheries Research Board Canada, $51830,1221-1225$.

519 Ianelli, J.N.; Honkalehto, T.; Barbeaux, S.; Kotwicki, S.; Aydin, K.; Williamson, N. (2011).

520 Assessment of the walleye pollock stock in the Eastern Bering Sea. Alaska Fisheries Science

521 Center, National Marine Fisheries Service.

522 Isaac, N.J.B.; Carbone, C. (2010). Why are metabolic scaling exponents so controversial?

523 Quantifying variance and testing hypotheses. Ecology Letters, 13, 728-735.

524 Jobes, F.W. (1946). The age, growth, and distribution of the longjaw cisco (Leucichthys alpenae

525 Koelz) in Lake Michigan. Transactions of the American Fisheries Society, 76, 215-247

526 Jørgensen, T. (1992). Long-term changes in growth of North-East Arctic cod (Gadus morhua) and 527 some environmental influences. ICES Journal of Marine Sciences, 49, 263278.

528 Juan-Jorda, M.J.; Mosqueira, I.; Freire, J.; Dulvy, N.K. (2015) Population declines of tuna and 529 relatives depend on their speed of life. Proc. Royal Society B, 282, doi: 10.1098/rspb.2015.0322

530 Kaushik, S.; Georga, I.; Koumoundouros, G. (2011). Growth and Body Composition of Zebrafish 531 (Danio rerio) Larvae Fed a Compound Feed from First Feeding Onward: Toward Implications on 532 Nutrient Requirements. Zebrafish, 8, 87-95.

533 Katsanevakis, S.; Maravelias, C.D. (2008). Modelling fish growth: multi-model inference as a 534 better alternative to a priori using von Bertalanffy equation. Fish and Fisheries 9, 178-187.

535 Killen, S.S., Atkinson, D., Glazier, D.S. (2010). The intraspecific scaling of metabolic rate with 536 body mass in fishes depends on lifestyle and temperature. Ecology Letters, 13, 184-193.

537 Kimura, D.K. (2008). Extending the von Bertalanffy growth model using explanatory variables. 538 Can. J. Fish. Aquat. Sci., 65, 1879-1891.

539 Kleiber, M. (1947). Body size and metabolic rate. Physiological Reviews. 27, 511-541.

540 Knight, W. (1968). Asymptotic growth, an example of nonsense disguised as mathematics.

541 Journal of the Fisheries Research Board of Canada, 25, 1303-1306.

542 Koch, V.; Rengstorf, A.; Taylor, M.; Mazon-Suastegui, J.M., Sinsel, F.; Wolff, M. (2015).

543 Comparative growth and mortality of cultured Lion's Paw scallops (Nodipecten subnodosus)

544 from Gulf of California and Pacific populations and their reciprocal transplants. Aquaculture

545 Research, 46, 185-201.

546 Krüger, F. (1973). Zur Mathematik des tierischen Wachstums. II. Vergleich einiger

547 Wachstumsfunktionen. Helgol. Wissenschaftliche Meeresuntersuchungen, 25, 509-550.

548 Leader, J. J. (2004). Numerical Analysis and Scientific Computation. Addison-Wesley, Boston.

549 Maceina, M.J. (2007). Use of piecewise nonlinear models to estimate variable size-related 550 mortality rates. North American Journal of Fisheries Management, 27, 971-977.

551 MacNeil, M.A.; Chong-Seng, K.M.; Pratchett, D.J.; Thompson, C.A.; Messmer, V.; Pratchett, 552 M.S. (2017). Age and Growth of a Outbreaking Acanthaster cf. solaris Population within the 553 Great Barrier Reef. Diversity, 9, doi:10.3390/d9010018. 
554 Mooij, W.M.; Van Rooij, J.M.; Wijnhoven, S. (1999). Analysis and comparison of fish growth

555 from small samples of length-at-age data: Detection of sexual dimorphism in Eurasian perch as

556 an example. Transactions of the American Fisheries Society, 128, 483-490.

557 Moreau, J. (1979). Biologie et evolution des peuplements de Clichlides (pisces) introduits dans

558 les lacs malgaches d'altitude. Doctoral Thesis at National Polytechnic Institute, Toulouse, France.

559 Motulsky, H.; Christopoulos, A. (2003). Fitting Models to Biological Data Using Linear and

560 Nonlinear Regression: A Practical Guide to Curve Fitting. Oxford Univ. Press, Oxford.

561 Ogle, D. (2017). R for Fisheries Analysis, derekogle.com, last accessed in August 2017.

562 Ohnishi, S.; Yamakawa, T; Akamine, T. (2014). On the analytical solution for the Pütter-

563 Bertalanffy growth equation. J. Theoretical Biology, 343, 174-177.

564 Owen, D.F. (1960). The nesting success of the Heron Ardea cinerea in relation to the availability

565 of food. Proc. Zool. Soc. London, 133, 597-617.

566 Parker, B.R.; Schindler, D.W.; Wilhelm, F.M.; Donald, D.B. (2007). Bull trout population

567 responses to reductions in angler effort and retention limits. North American Journal of Fisheries

568 Management, 27, 848-859

569 Parks, J.R. (1982). A theory of feeding and growth of animals. Reprinted 2012 by Springer

570 Business Media, New York.

571 Pauly, D. (1979). Gill size and temperature as governing factors in fish growth: a generalization

572 of von Bertalanffy's growth formula. Doctoral thesis, University of Kiel, Germany.

573 Pei, K. (1996). Post-natal Growth of the Formosan Reeves' Muntjac Muntiacus reevesi Micrurus.

574 Zoological Studies, 35, 111-117.

575 Piner, K.R.; Hui-Hua, L.; Maunder, M.M. (2016). Evaluation of using random-at-length

576 observations and an equilibrium approximation of the population age structure in fitting the von

577 Bertalanffy growth function. Fisheries Research, 180, 128-137.

578 Porch, C.E. (2002). A new growth model for red drum (Sciaenops ocellatus) that accommodates

579 seasonal and ontogenic changes in growth rates. Fishery Bulletin, 100, 149-152.

580 Pratchett, M.S. (2005). Dynamics of an outbreak population of Acanthaster planci at Lizard

581 Island, northern Great Barrier Reef (1995-1999). Coral Reefs, 24, 453-462.

582 Pütter, A. (1920). Studien über physiologische Ähnlichkeit. VI. Wachstumsähnlichkeiten. Pflüg.

583 Archiv der Gesamten Physiologie, 180, 298-340.

584 Quince, C.; Abrams, P.A.; Shuter, B.J.; Lester, N.P. (2008). Biphasic growth in fish I: theoretical 585 foundations. J. Theoretical Biology, 254, 197-206.

586 Quist, M.C.; Pegg, M.A.; DeVries, D.R. (2012). Chapter 15. Age and growth. In Zale, A.V.;

587 Parrish, D.L.; Sutton, T.M. (Editors). Fisheries Techniques, American Fisheries Society,

588 Bethesda, MD, pp 677-731.

589 Read, A.J.; Wells, R.S.; Hohn, A.A.; Scott, M.D. (1993). Pattern of growth in wild bottlenose

590 dolphins (Tusiops truncatus). J. Zool. London, 231, 107-123. 
591 Reid, S.M. (2004). Age estimates and length distributions of Ontario channel darter (Percina

592 copelandi) populations. Journal of Freshwater Ecology, 19, 441-444.

593 Renner-Martin, K.; Kühleitner, M.; Brunner, N.; Hagmüller, W. (2016). AIC-Based Selection of

594 Growth Models: The Case of Piglets from Organic Farming. Open Journal of Modelling and

595 Simulation, 4, 17-23.

596 Ricard, F.H. (1975). Essai de selection sur la forme de la courbe de croisance chez Ie poulet.

597 Annales Genet. Select. Anim., 7, 427-443.

598 Richards, F.J. (1959). A Flexible Growth Function for Empirical Use, Journal of Experimental

599 Botany, 10, 290-300.

600 Rudstam, LG. (1989). A bioenergetic model for Mysis growth and consumption applied to a

601 Baltic population of Mysis mixta. J. Plankton Res., 11, 971-983.

602 Schnute, J.; Fournier, D. (1980). A new approach to length-frequency analysis: growth structure.

603 Canadian J. Fisheries \& Aquatic Sciences, 37, 1337-1351.

604 Shi, P.-J.; Ishikawa, T.; Sandhu, H.S.; Hui, C.; Chakraborty, A.; Jin, X.-S.; Tachihara, K.; Li, B.605 L. (2014). On the 3/4-exponent van Bertalanffy equation for ontogenetic growth. Ecological 606 Modelling, 276, 23-28.

607 Smart, J.J.; Chin, A.; Tobin, A.J.; Simpfendorfer, C.A. (2016), Multimodel approaches in shark 608 and ray growth studies: strengths, weaknesses and the future. Fish and Fisheries, 17, 955-971.

609 Smuts, G.L. (1975). Pre- and post-natal growth phenomena of Burchell's Zebra Equuus burchelli 610 antiquorum. Koedoe, 18, 69-102.

611 Sparre, T.; Venema, S.C. (1988). Introduction to tropical fish stock assessment. Part I Manual.

612 FAO Fisheries and Aquaculture Technical Paper Series, FAO, Rome, Italy.

613 Stewart, J.; Robbins, W.D.; Rowling, K.; Hegarty, A.; Gould, A. (2013). A multifaceted approach

614 to modelling growth of the Australian bonito, Sarda australis (Family Scombridae), with some

615 observations on its reproductive biology. Mar. Freshw. Research, 64, 671-678.

616 Strathe, A.B.; Danfær, A.; Sørensen, H.; Kebreab, E. (2010). A multilevel nonlinear mixed-effects 617 approach to model growth in pigs. J. Anim. Sci., 88, 638-649.

618 Sturm, R. (2003). Längen- und Gewichtsentwicklung der Larven verschiedener Grillenarten

619 (Orthoptera: Gryllidae) vom Zeitpunkt des Ausschlüpfens bis zur Adulthäutung. Linzer

620 biologische Beiträge., 35, 487-498.

621 Vaughan, D.S.; Helser, T.E. (1990). Status of the red drum stock of the Atlantic Coast: Stock

622 assessment report for 1989. NOAA Technical Memorandum, NMFS-SEFC-263.

623 Verhulst, P.F. (1838). Notice sur la loi que la population suit dans son accroissement,

624 Correspondence Mathematique et Physique (Ghent), 10, 113-121.

625 Walford, L. (1946). A new graphic method of describing the growth of animals. Biol. Bull., 90, 626 141-147.

627 West, G.B.; Brown, J.H.; Enquist, B.J. (2001). A general model for ontogenetic growth. Nature, $628413,628-631$. 
629 White, C.R.; Seymour, R.S. (2003). Mammalian basal metabolic rate is proportional to body $630 \operatorname{mass}^{\wedge} 2 / 3$. Proc. Natl. Acad. Sci. U.S.A., 100, 4046-4049.

631 White, C.R. (2010). Physiology: There is no single p. Nature, 464, 691-693.

632 Wolfert, D.R. (1980). Age and growth of rock bass in Eastern Lake Ontario. New York Fish and 633 Game Journal, 27, 88-90.

634 Yamamoto, Y.; Kao, S.J. (2012). Relationship between Latitude and Growth of Bluegill Lepomis 635 macrochirus in Lake Biwa, Japan. Ann. Zool. Fennicae, 49, 36-44.

636 Yildirim, A.; Haluloulu, H.U.; Turkmen, M.; Erdouan, O. (2003). Age and growth characteristics 637 of Chalcalburnus mossulensis (Heckel, 1843) living in Karasu River (Erzurum-Turkey). Turkish 638 Journal of Veterinary and Animal Science, 27, 1091-1096. 


\section{Figure 1}

Right hand side of equation (1) compared to observed values for the left hand side of (1)

Figure generated in Microsoft EXCEL based on data set \#10 (outlier removed). Squares indicate observed growth rates, the left hand side of equation (1), whereby $d m / d t$ was computed by numeric differentiation (quadratic interpolation taking care of unequal $\mathrm{dt}$ interval length: Burden and Faires, 1993). The line (model) is the right hand side of equation (1). Its parameters ( $p=323, q=0.73$ ) were obtained from a linear fit to the observed growth rates (LINEST function of EXCEL applied to $d m / d t, m^{a}$, and $m$ with $a=2 / 3$ ). This method of fitting parameters is a modification of the Walford plot (Walford, 1946).

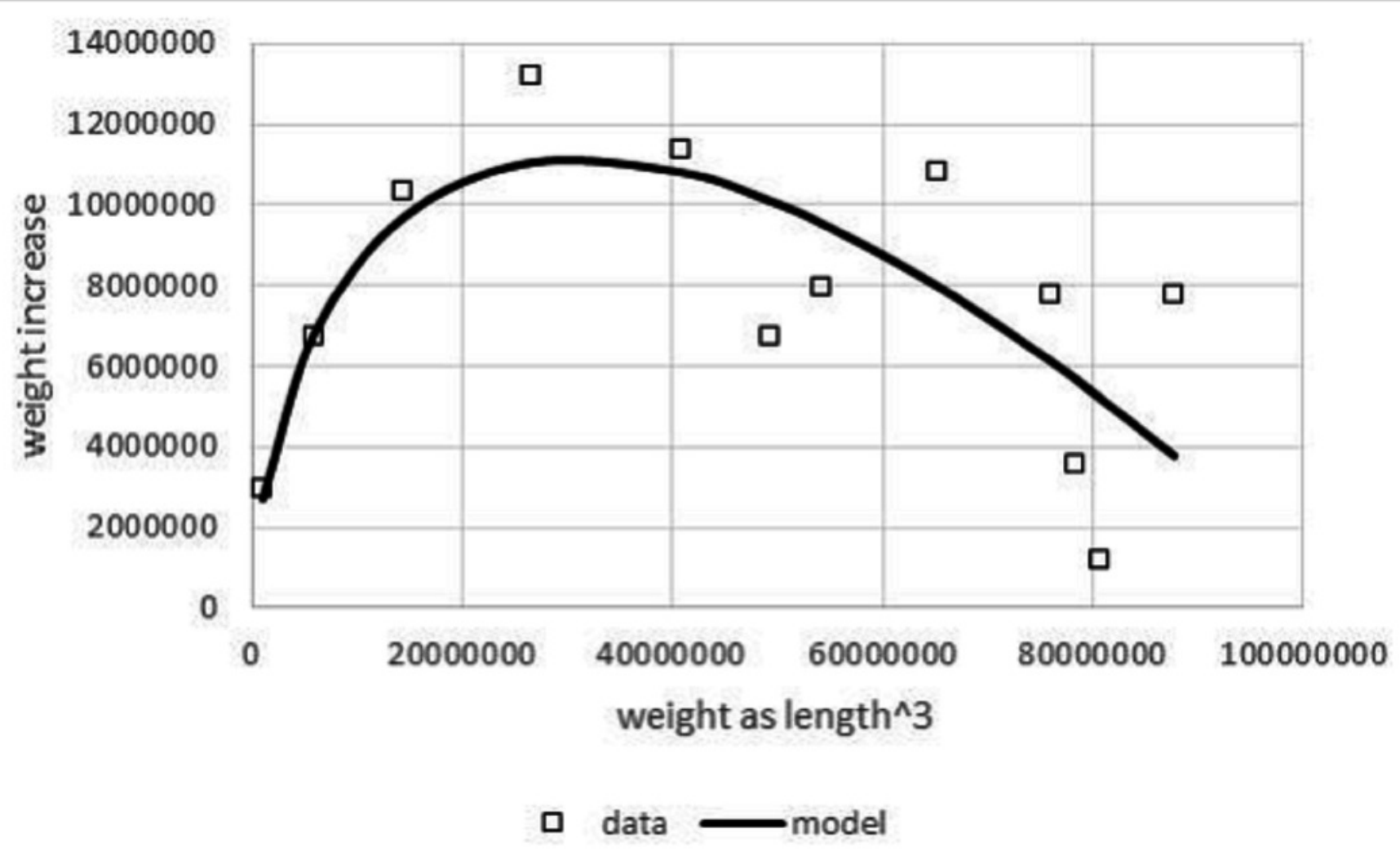


Figure 2

Explanation of the meaning of 'full growth phase'

The figure illustrates $a)$ the general form of VBGF $\left(a=2 / 3, m_{0}=5, m_{\max }=100, q=0.01\right)$ showing a characteristic S-shape (circle $=$ inflection point: $m_{\text {infl }}=29.6$ at age $=95.9$ ) over its whole range; b) missing end-data, which suggest unbounded growth; and c) missing data at the beginning, which suggests exponential bounded growth (exponent $a=0$ ).

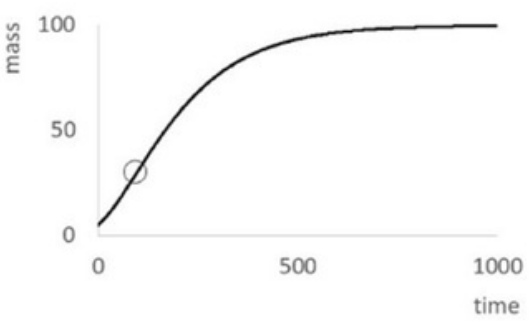

a) full growth

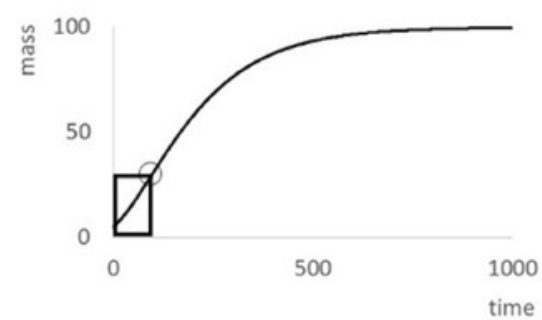

b) initial phase

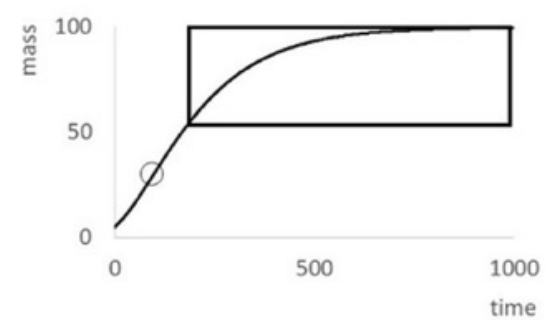

c) final phase 
Figure 3

Comparing the fit of model (1) with different exponents to growth data

Figure generated in Microsoft EXCEL, based on data set \#3 and the least squares fit to these data of model (1); squares: data (weight as length^ 3 ); dashed line: model curve for the exponent $a=0.67\left(m_{0}=0.14, m_{\max }=23,538, q=0.18\right)$; thick line: model curve for the optimal exponent $a=0.99\left(m_{0}=0.14, m_{\max }=23,538, q=26.4\right)$.

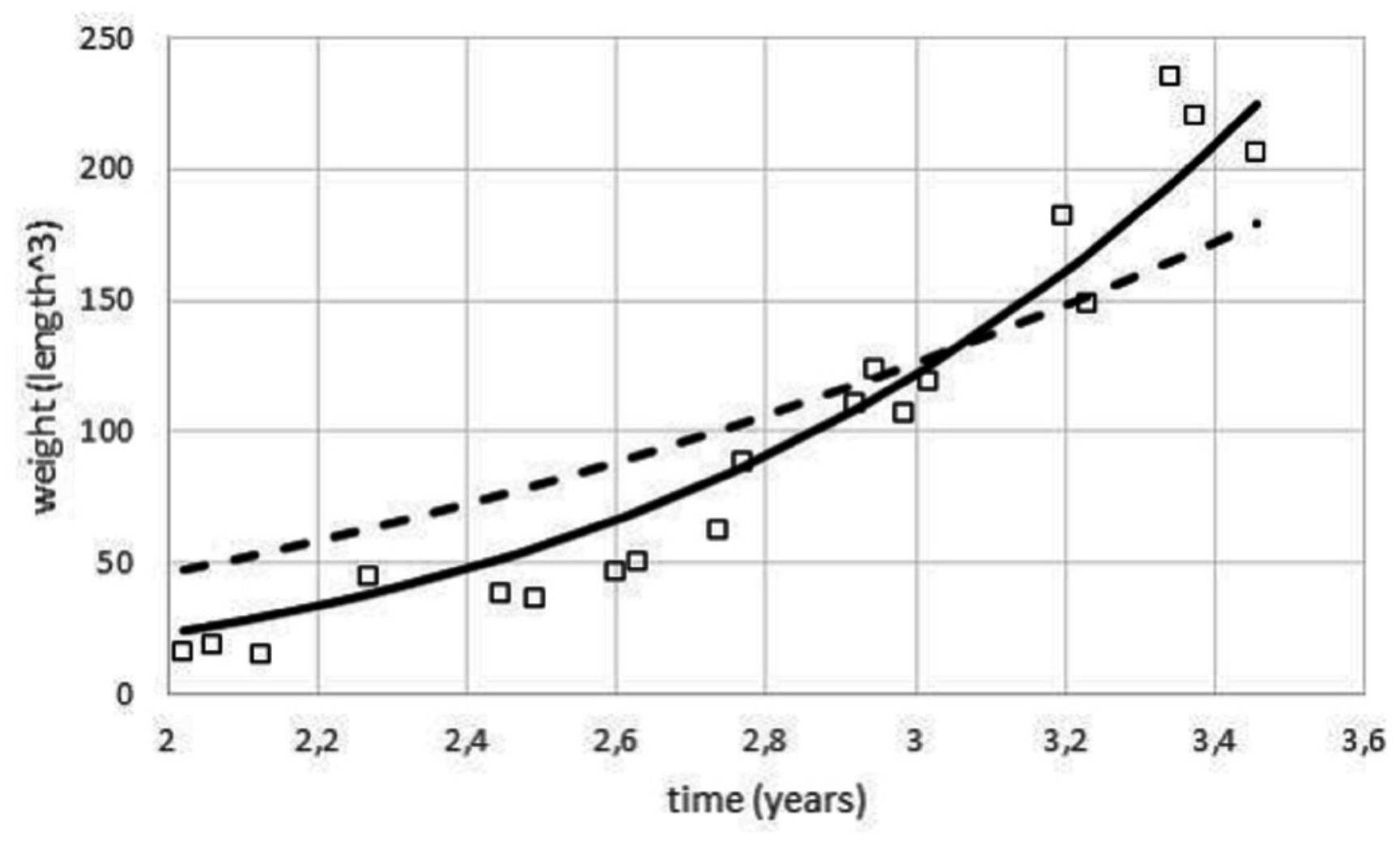




\section{Figure 4}

Transformation of time-mass-data and a regression line for the transformed data set

Generalized Bertalanffy-Beverton plot generated in Microsoft EXCEL, based on data set \#47; squares: transformation of data $(t, m)$ into $(u, t)=(f(m), t)$; line: regression line $t=A+B \cdot u$ with $A=-55.64$ and $B=-14.03$. The function $f$ was defined in equation (3) using the exponent $a$ $=0.83$ and assuming an asymptotic weight limit $m_{\max }=32,163 \mathrm{~g}$. The transformation required $m_{\max }$ to exceed the maximal observed weight $(31.8 \mathrm{~kg})$, as otherwise the transformation would not be defined for all data points.

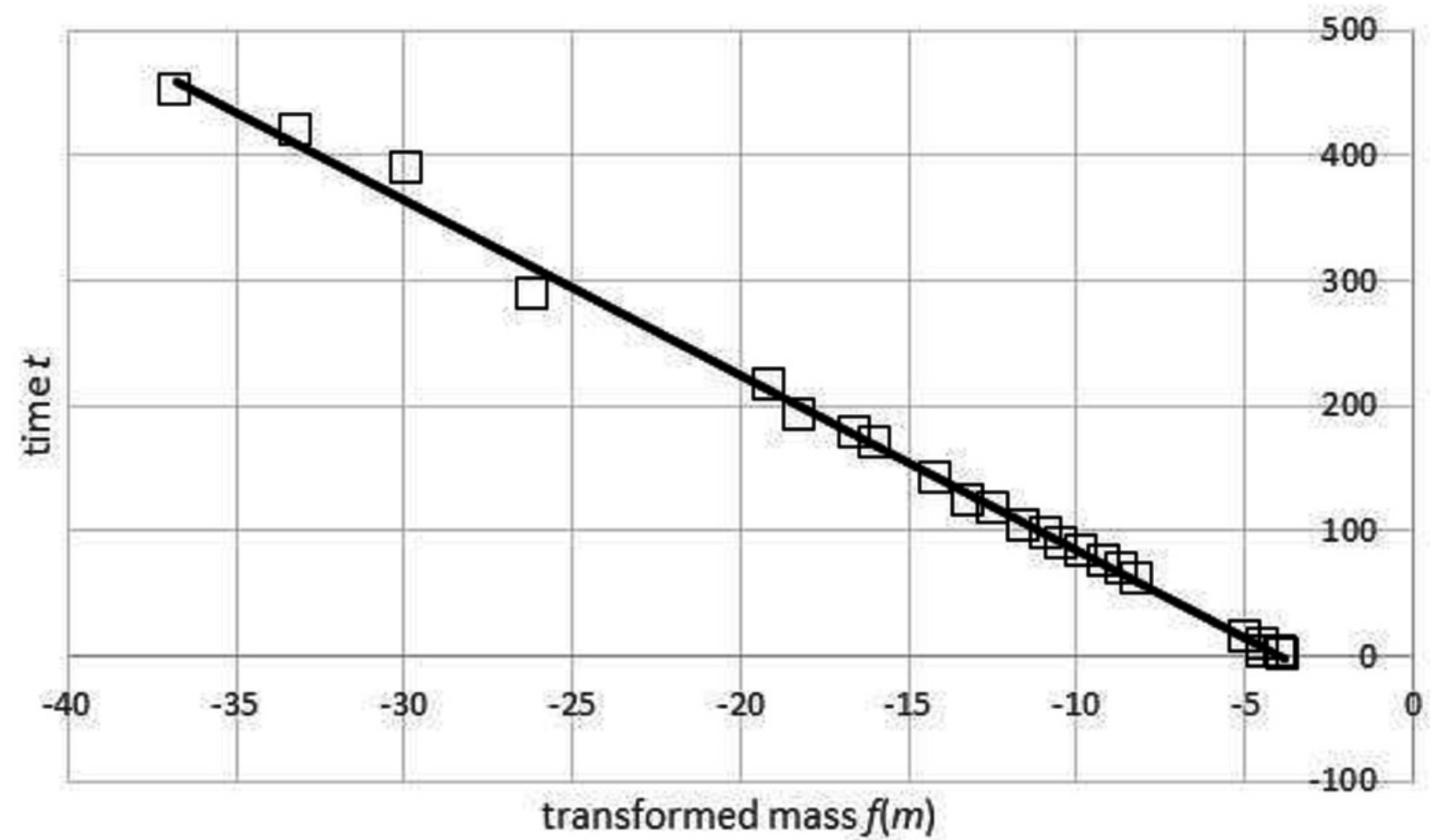


Figure 5

Optimizing the asymptotic weight limit (fit to weight-time data)

Figure generated in Microsoft EXCEL, based on data set \#14, plotting the sum of squared residuals $S S R_{i n v}$ (fit to the weight-time data) in dependency on $m_{\max }$ for an exponent $a=0.67$.

The minimum was attained for $m_{\max }=0.165 \mathrm{~g}$ (maximal observed weight: $m_{o b s}=0.145 \mathrm{~g}$ ) resulting in the estimates $q=0.1 /$ day and $m_{0}=0.03 \mathrm{~g}$. These were used as a starting value for the minimization of SSR (fit to the time-weight data). The resulting optimal parameters for $a=0.67$ were $q=0.139 /$ day, $m_{0}=0.002 \mathrm{~g}$ and $m_{\max }=0.149 \mathrm{~g}$.

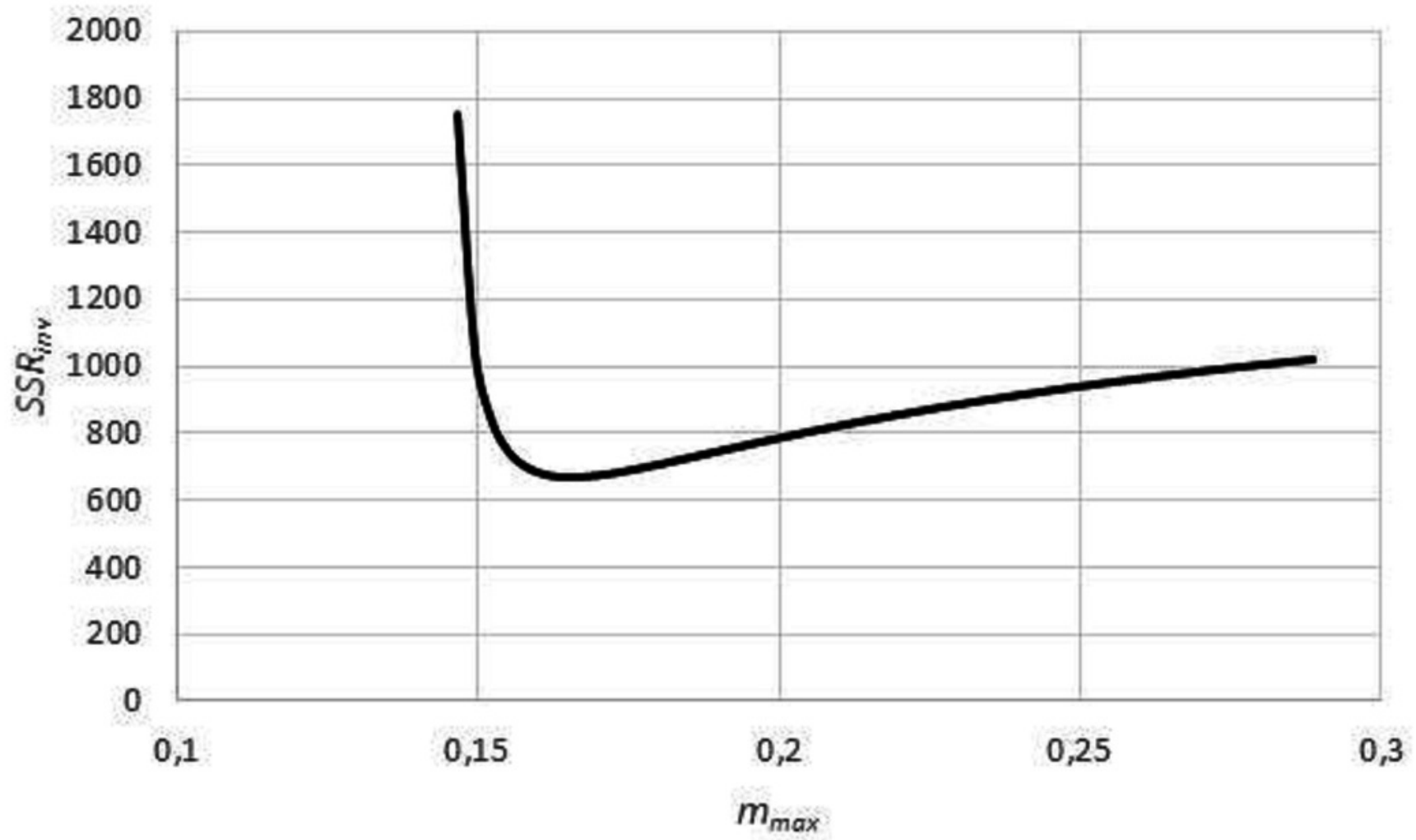




\section{Figure 6}

Akaike weights for different exponents, for data with and without outliers

Graphical multi-model comparison, generated in Microsoft EXCEL, based on data set \#10 with and without outlier. The Akaike weight $\operatorname{prob}(a)$ for model (1) with exponent a was computed in comparison with the optimal exponent; dashed/fat line Akaike weights for data with/without outlier. Without outlier, the optimal exponent became larger (0.64) and exponents with poor fit could be discerned more easily.

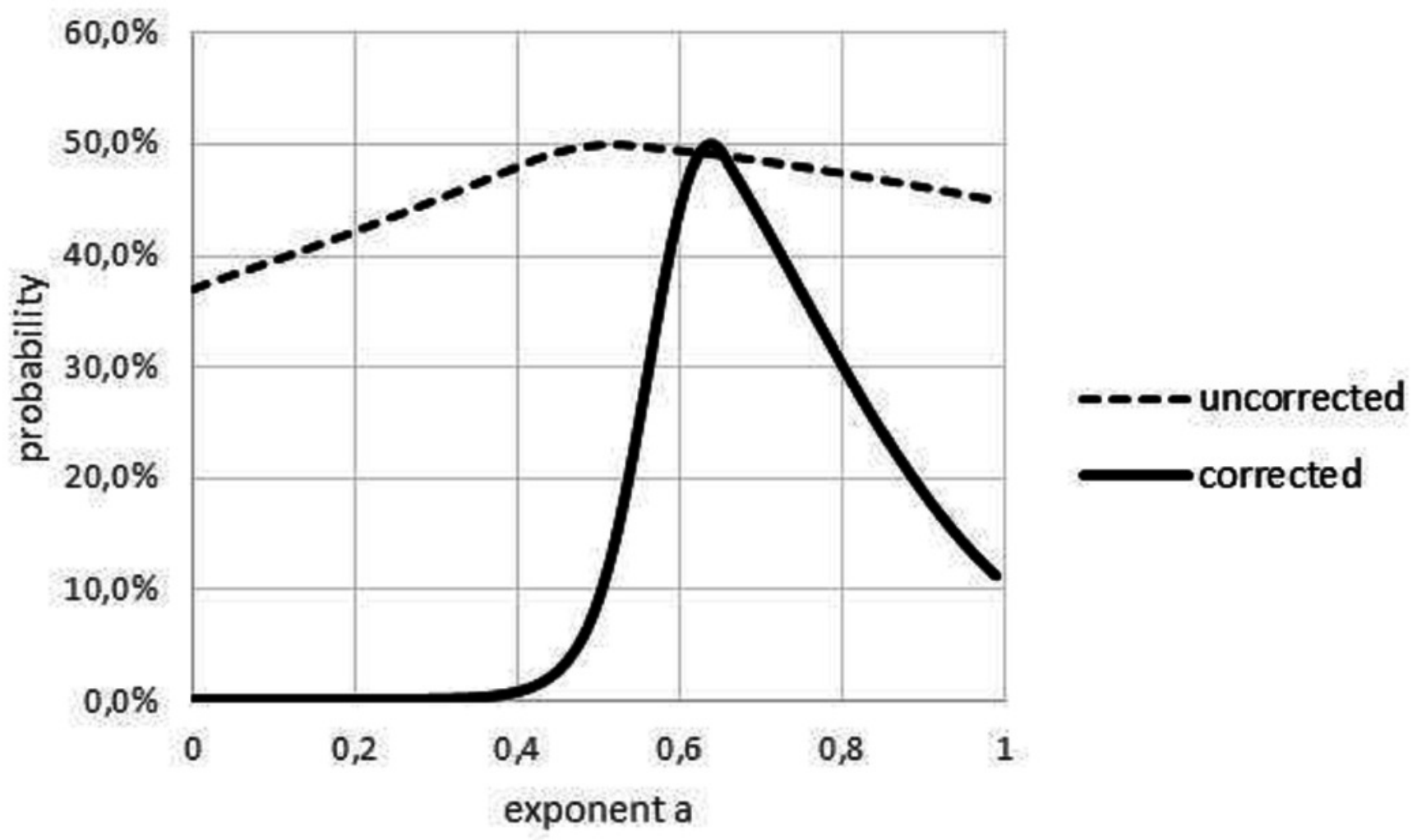


Figure 7

Confidence intervals for the percentage of data sets not rejecting an exponent

Figure generated in Microsoft EXCEL. Fat curve counting the percentage of how many of the 60 data sets did not reject the exponent $a$; thin curves one-sided Clopper-Pearson confidence limits (95\% significance).

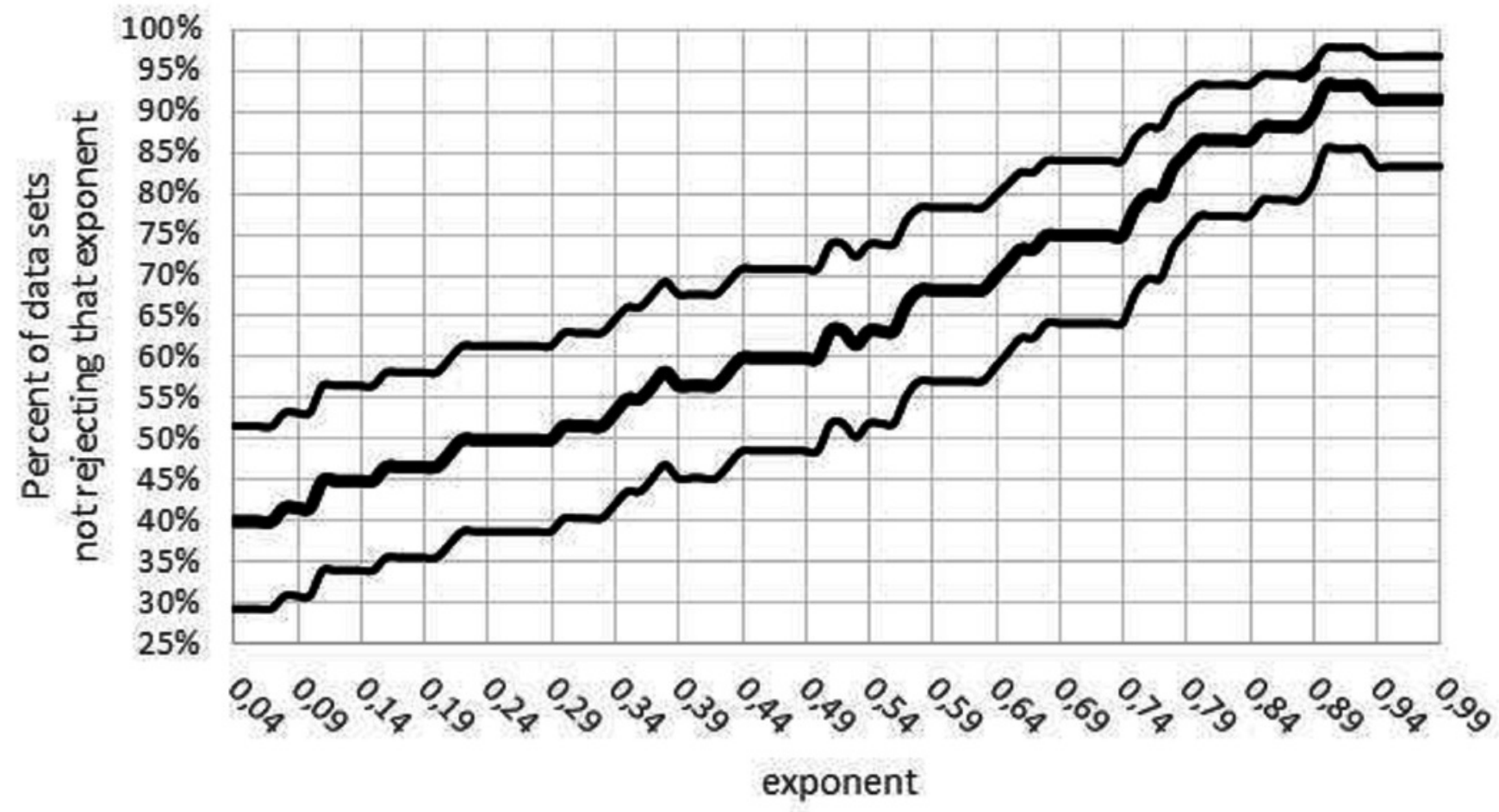


Figure 8

Effect on the Akaike weights of using different length-mass relations

Figure generated in Microsoft EXCEL, based data set \#2, plotting Akaike weights for modifications of the data set, using different powers of length to estimate mass.

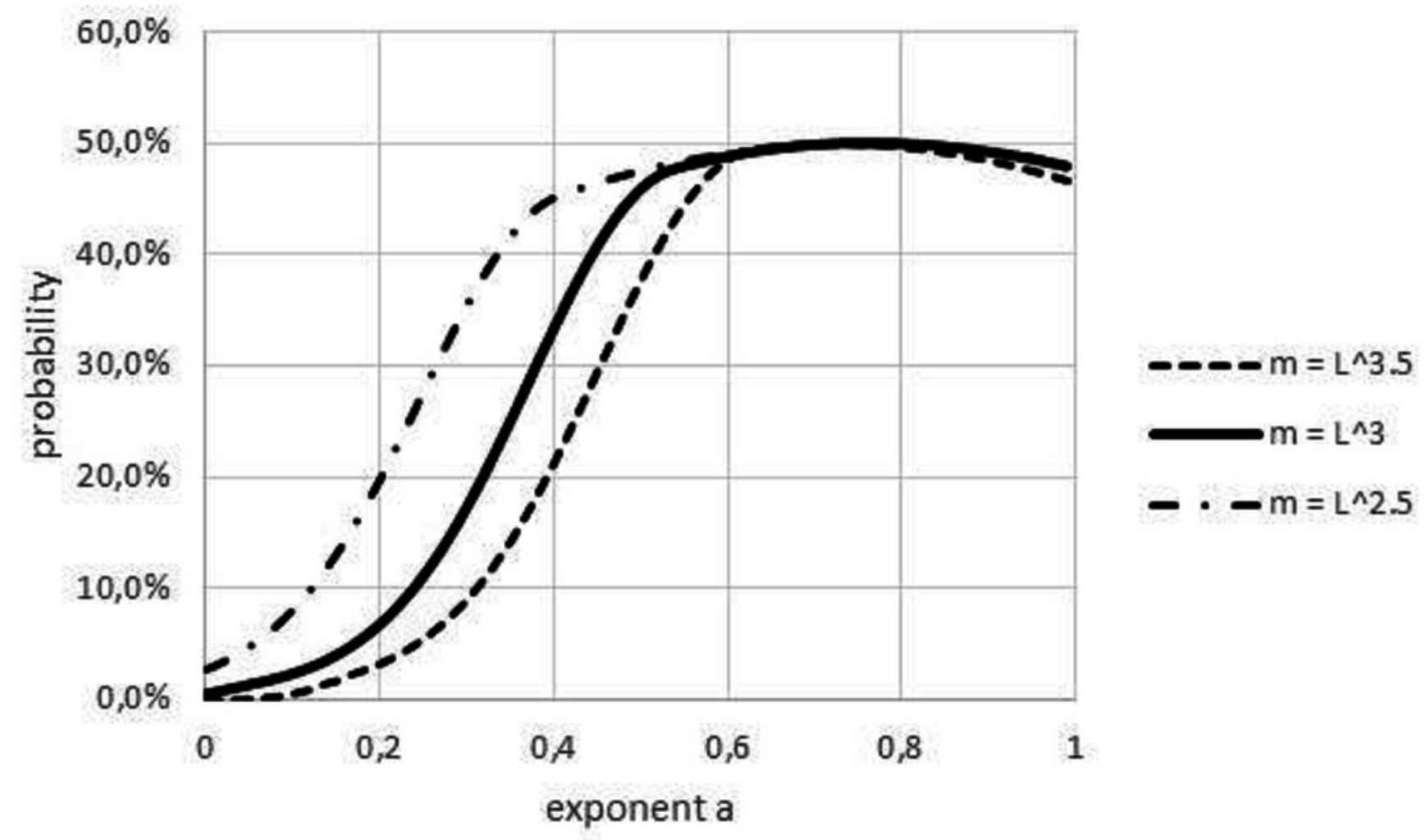


Figure 9

Effect of combining males and females on the Akaike weights

Figure generated in Microsoft EXCEL, based on data sets \#18 and \#19, plotting Akaike weights for data separated by sex and for the combined data.

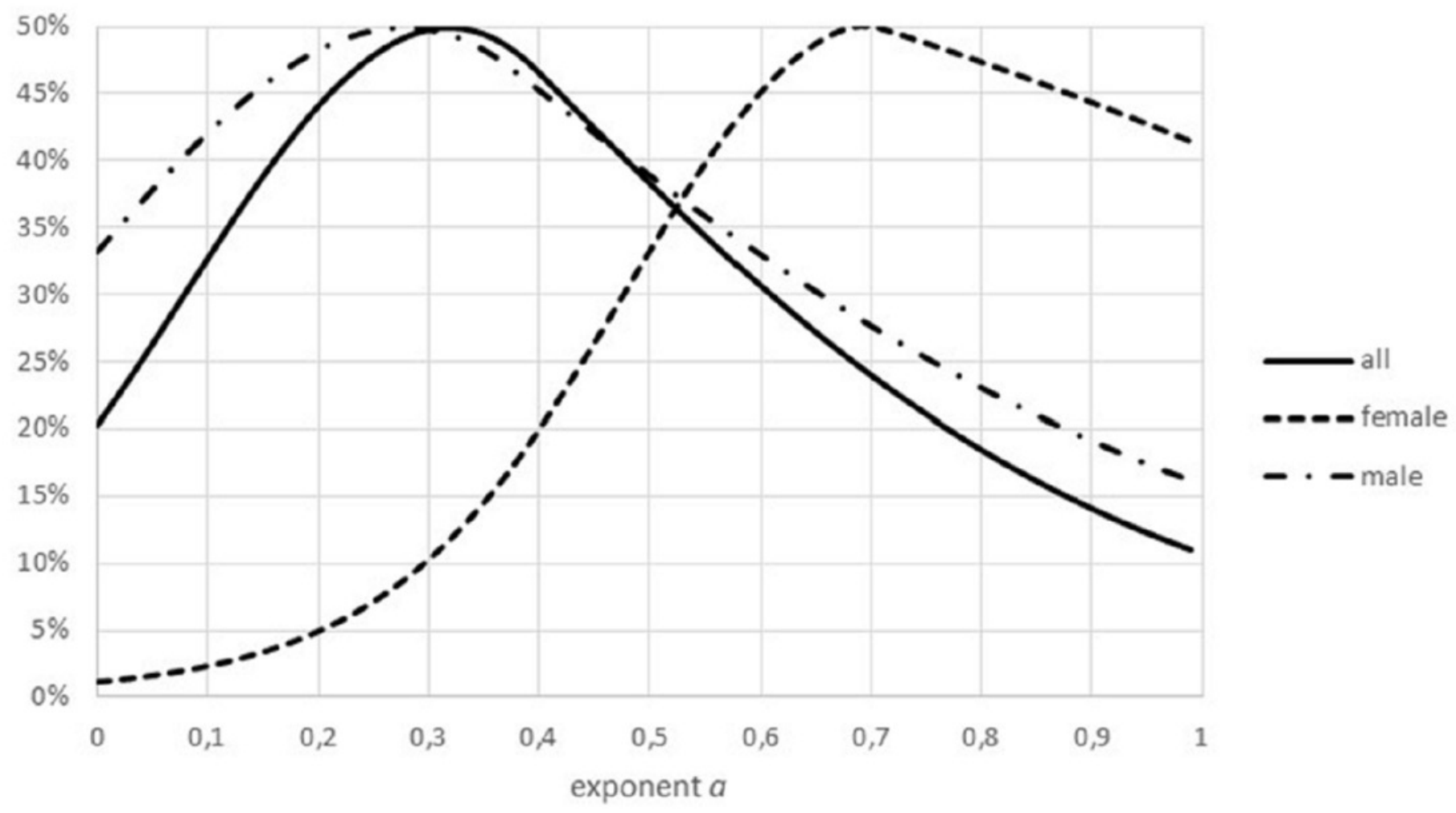




\section{Table $\mathbf{1}$ (on next page)}

Numbering and sources of the fish data

Data: number of time points, * time points minus outlier (removed by the authors); comment:

$\mathrm{C} / \mathrm{N}$ controlled/natural data, TL/TW time length/weight data, $\mathrm{F} / \mathrm{M} / \mathrm{L}=$ female/male/larvae 


\begin{tabular}{|c|c|c|c|c|c|}
\hline No & Name & & Data & Comment & Source \\
\hline 1 & Anchoveta & Engraulis ringens & 46 & \multirow{3}{*}{$\mathrm{N}, \mathrm{TL}$} & \multirow{2}{*}{ Cubillos et al. (2001) } \\
\hline 2 & Araucanian Herring & Strangomera bentincki & 36 & & \\
\hline 3 & Atlantic (Arctic) Cod & Gadus morhua & 19 & & Jørgensen (1992) \\
\hline 4 & Black Drum & Pogonias cromis & 8 & $\mathrm{~N}, \mathrm{TL}, \mathrm{F}$ & Ogle (2017) \\
\hline 5 & Blue Catfish & Ictalurus furcatus & 21 & $\mathrm{~N}, \mathrm{TL}$ & Maceina (2007) \\
\hline 6 & \multirow{2}{*}{ Australian Bonito } & \multirow{2}{*}{ Sarda australis } & 33 & $\mathrm{~N}, \mathrm{TL}, \mathrm{F}$ & \multirow{2}{*}{ Stewart et al. (2013) } \\
\hline 7 & & & 20 & $\mathrm{~N}, \mathrm{TL}, \mathrm{M}$ & \\
\hline 8 & $\begin{array}{l}\text { Sea Trout \& } \\
\text { Rainbow Trout }\end{array}$ & $\begin{array}{l}\text { Salmo trutta \& } \\
\text { Oncorhynchus mykiss }\end{array}$ & 9 & \multirow{6}{*}{$\mathrm{N}, \mathrm{TL}$} & Ogle (2017) \\
\hline 9 & Sea (Brown) Trout & Salmo trutta fario & 15 & & Abad (1982) \\
\hline 10 & Bull Trout & Salvelinus confluentis & $14^{*}$ & & Parker et al. (2007) \\
\hline 11 & Cabezon & Scorpaenichthys marmoratus & 13 & & \multirow{2}{*}{ Ogle (2017) } \\
\hline 12 & Atlantic Croaker & Micropogonias undulatus & 10 & & \\
\hline 13 & European Perch & Perca fluviatilis & 8 & & Mooij et al. (1999) \\
\hline 14 & Guppy & Poecilia reticulate & 14 & $\mathrm{C}, \mathrm{TW}$ & Brown \& Rothery (1993) \\
\hline 15 & Jackass Morwang & Nemadactylus macropterus & 16 & \multirow{3}{*}{$\mathrm{N}, \mathrm{TL}$} & Ogle (2017) \\
\hline 16 & Jonubi & Chalcalburnus mossulensis & 6 & & Yildirim (2003) \\
\hline 17 & Lake Erie Walleye & Sander vitreus & 20 & & \multirow{3}{*}{ Ogle (2017) } \\
\hline 18 & \multirow{2}{*}{ Arctic Lake Trout } & \multirow{2}{*}{ Salvelinus namaycush } & 17 & $\mathrm{~N}, \mathrm{TL}, \mathrm{F}$ & \\
\hline 19 & & & 19 & $\mathrm{~N}, \mathrm{TL}, \mathrm{M}$ & \\
\hline 20 & Longjaw Cisco & Coregonus alpenae (extinct) & 8 & \multirow{5}{*}{$\mathrm{N}, \mathrm{TL}$} & Jobes (1946) \\
\hline 21 & Red Drum & Sciaenops ocellatus & 42 & & Vaughan \& Helser (1990) \\
\hline 22 & Redbreast Tilapia & Coptodon rendalli & 19 & & Moreau (1979) \\
\hline 23 & Rock Bass & Ambloplites rupestris & 9 & & Wolfert (1980) \\
\hline 24 & Round Whitefish & Prosopium cylindraceum & 9 & & Bailey (1963) \\
\hline 25 & Sockeye Salmon & Oncorhynchus nerka & 24 & $\mathrm{~N}, \mathrm{TW}$ & West et al. (2001) \\
\hline 26 & Sardine & Strangomera bentincki & 37 & $\mathrm{~N}, \mathrm{TL}$ & Cubillos et al. (2001) \\
\hline 27 & \multirow{2}{*}{ Siscowet Lake Trout } & \multirow{2}{*}{ Salvelinus namaycush } & 15 & $\mathrm{~N}, \mathrm{TL}, \mathrm{F}$ & \multirow{2}{*}{ Ogle (2017) } \\
\hline 28 & & & 10 & $\mathrm{~N}, \mathrm{TL}, \mathrm{M}$ & \\
\hline 29 & Spotted Sucker & Minytrema melanops & 7 & \multirow{5}{*}{$\mathrm{N}, \mathrm{TL}$} & Grabowski et al. (2012) \\
\hline 30 & Atlantic Bluefin Tuna & Thunnus thynnus & 14 & & Krüger (1973) \\
\hline 31 & Troutperch & Percopsis omsicomaycus & 8 & & House \& Wells (1973) \\
\hline 32 & Virgina Spot & Leiostomus xanthurus & 6 & & Ogle (2017) \\
\hline 33 & Walleye Pollock & Theragra chalcogramma & 15 & & Ianelli et al. (2011) \\
\hline 34 & \multirow{2}{*}{ White Grunt } & \multirow{2}{*}{ Haemulon plumierii } & 110 & $\mathrm{~N}, \mathrm{TL}, \mathrm{F}$ & \multirow{2}{*}{ Araujo \& Martins (2007) } \\
\hline 35 & & & 104 & $\mathrm{~N}, \mathrm{TL}, \mathrm{M}$ & \\
\hline 36 & \multirow{2}{*}{ Zebrafish } & \multirow{2}{*}{ Danio rerio } & 7 & $\mathrm{C}, \mathrm{TW}, \mathrm{M}$ & Gomez-Requeni (2010) \\
\hline 37 & & & 7 & $\mathrm{C}, \mathrm{TL}, \mathrm{L}$ & Kaushik et al. (2011) \\
\hline
\end{tabular}




\section{Table 2 (on next page)}

Numbering and sources of non-fish time-weight data from controlled experiments

Data: number of time points; comment: $F / M=$ female/male, if for the same species data sets of male and female animals were considered (all data sets except \#60 were unisex); Source: $\mathrm{PC}=$ personal communication 


\begin{tabular}{|c|c|c|c|c|c|}
\hline No & \multicolumn{2}{|l|}{ Name } & Data & Comment & Source \\
\hline 38 & \multirow{2}{*}{ Cattle } & \multirow{2}{*}{ Bos primigenius Taurus } & 21 & strain unknown & Brody (1945) \\
\hline 39 & & & 42 & Friesian & Parks (1982) \\
\hline 40 & \multirow{7}{*}{ Chicken } & \multirow{7}{*}{ Gallus gallus domesticus } & 19 & strain unknown & Brody (1945) \\
\hline 41 & & & 30 & Apollo & Parks (1982) \\
\hline 42 & & & 11 & Rhode Island & Grossmann (1969) \\
\hline 43 & & & 30 & Ross Fryer & Parks (1982) \\
\hline 44 & & & 20 & X33 strain & \multirow{3}{*}{ Ricard (1975) } \\
\hline 45 & & & 20 & X38 strain & \\
\hline 46 & & & 20 & X44 strain & \\
\hline 47 & \multirow{3}{*}{ Dog } & \multirow{3}{*}{ Canis lupus familiaris } & 23 & Rhodesian Ridgeback & PC: Elke Schläger \\
\hline 48 & & & 60 & Great Dane, $\mathrm{F}$ & \multirow{2}{*}{ Parks (1982) } \\
\hline 49 & & & 60 & Great Dane, $M$ & \\
\hline $\mathbf{5 0}$ & Domestic Pig & Sus scrofa domestica & 100 & various strains & Renner-Martin et al. (2016) \\
\hline 51 & \multirow{3}{*}{ Cricket } & Acheta domesticus & 11 & \multirow{3}{*}{ larvae } & \multirow{3}{*}{ Sturm (2003) } \\
\hline 52 & & Gryllus assimilis & 11 & & \\
\hline 53 & & Teleogryllus commodus & 11 & & \\
\hline 54 & Heron & Ardea cinerea & 12 & & Owen (1960) \\
\hline 55 & Ball Python & Python regius & 14 & & PC: Fabian Bader \\
\hline 56 & \multirow{2}{*}{ Rat } & \multirow{2}{*}{ Rattus rattus } & 21 & albino & Parks (1982) \\
\hline 57 & & & 17 & strain unknown & Brody (1945) \\
\hline 58 & Robin & Erithacus rubecula & 12 & & Owen (1960) \\
\hline 59 & Shrew & Sorex cinereus & 12 & & Forsyth (1976) \\
\hline 60 & Shrimp & Mysis mixta & 7 & & Rudstam (1989) \\
\hline
\end{tabular}

2 


\section{Table 3 (on next page)}

Optimal exponents and range of acceptable exponents

Data sets numbered as in Tables1 and 2; abbreviations for max: 'NO' no problem with $m_{\max \text { ' }}$ 'A' and 'B' excessive $m_{\max }$, because $m_{\text {infl }} \geq m_{\text {obs' }}$, and because $m_{\max } \geq 1.5 \cdot m_{\text {obs, }}$, respectively, and ' $C$ ' $m_{\max }=m_{\text {obs }}$; $a_{\text {opt }}=$ exponent with the best fit of model (1) to the data; non-refutation: lower and upper bounds of the interval consisting of those of exponents that in comparison to $a_{\text {opt }}$ were not be refuted (Akaike weight $2.5 \%$ or higher). 
1

\begin{tabular}{|c|c|c|c|c|c|c|c|c|c|c|c|c|c|c|}
\hline \multirow{2}{*}{ No } & \multirow[b]{2}{*}{$a_{\text {opt }}$} & \multirow{2}{*}{$\Xi \underset{\sigma}{\Xi}$} & \multicolumn{2}{|c|}{ Non-refutation } & \multirow{2}{*}{ No } & \multirow[b]{2}{*}{$a_{\text {opt }}$} & \multirow{2}{*}{$\Xi \underset{\sigma}{\star}$} & \multicolumn{2}{|c|}{ Non-refutation } & \multirow{2}{*}{ No } & \multirow[b]{2}{*}{$a_{o p t}$} & \multirow{2}{*}{$\Xi \approx$} & \multicolumn{2}{|c|}{ Non-refutation } \\
\hline & & & Low & High & & & & Low & High & & & & Low & High \\
\hline 01 & 0.83 & \multirow{2}{*}{ NO } & 0.43 & 0.99 & 21 & 0 & & 0 & 0.99 & 41 & 0.85 & $\mathrm{C}$ & 0.65 & 0.99 \\
\hline 02 & 0.76 & & 0.11 & 0.99 & 22 & 0.62 & & 0.51 & 0.99 & 42 & 0.99 & \multirow{6}{*}{ NO } & 0.75 & 0.99 \\
\hline $\mathbf{0 3}$ & 0.99 & A & 0.9 & 0.99 & 23 & 0.57 & $\mathrm{P}$ & 0 & 0.99 & 43 & 0.99 & & 0.79 & 0.99 \\
\hline 04 & 0.39 & $\mathrm{NO}$ & 0.21 & 0.99 & 24 & 0.51 & B & 0.35 & 0.99 & 44 & 0.88 & & 0.78 & 0.99 \\
\hline 05 & 0.75 & $\mathrm{C}$ & 0 & 0.99 & 25 & 0.91 & \multirow{2}{*}{ NO } & 0.64 & 0.99 & 45 & 0.99 & & 0.9 & 0.99 \\
\hline 06 & 0 & \multirow{3}{*}{ NO } & 0 & 0.99 & 26 & 0.99 & & 0.34 & 0.99 & 46 & 0.99 & & 0.85 & 0.99 \\
\hline 07 & 0 & & 0 & 0.99 & 27 & 0.91 & $\mathrm{C}$ & 0.01 & 0.99 & 47 & 0.83 & & 0.68 & 0.99 \\
\hline 08 & 0.99 & & 0 & 0.99 & 28 & 0.99 & $\mathrm{NO}$ & 0.02 & 0.99 & 48 & 0.84 & \multirow{2}{*}{$\mathrm{C}$} & 0. & 0.99 \\
\hline 09 & 0.66 & A & 0.54 & 0.99 & 29 & 0.99 & A & 0 & 0.99 & 49 & 0.99 & & 0. & 0.99 \\
\hline 10 & 0.64 & \multirow{2}{*}{ NO } & 0.44 & 0.99 & 30 & 0.11 & $\mathrm{~B}$ & 0 & 0.99 & 50 & 0.45 & A & 0.37 & 0.93 \\
\hline 11 & 0.6 & & 0 & 0.99 & 31 & 0.19 & 4 & 0 & 0.99 & 51 & 0.99 & \multirow{4}{*}{ NO } & 0. & 0.99 \\
\hline 12 & 0 & $\mathrm{~B}$ & 0 & 0.99 & 32 & 0.99 & & 0 & 0.99 & 52 & 0.94 & & 0.75 & 0.99 \\
\hline $13^{\mathrm{c}}$ & 0.8 & $\mathrm{C}$ & 0 & 0.99 & 33 & 0.37 & & 0.22 & 0.67 & 53 & 0.99 & & 0.89 & 0.99 \\
\hline 14 & 0.99 & $\mathrm{NO}$ & 0.51 & 0.99 & 34 & 0.01 & \multirow{2}{*}{ C } & 0.01 & 0.99 & 54 & 0.99 & & 0.78 & 0.99 \\
\hline 15 & 0.99 & $\mathrm{~A}$ & 0 & 0.99 & 35 & 0 & & 0 & 0.99 & 55 & 0.99 & C & 0.57 & 0.99 \\
\hline 16 & 0.99 & B & 0.08 & 0.99 & 36 & 0.99 & \multirow{2}{*}{ NO } & 0.66 & 0.99 & 56 & 0.14 & NO & 0 & 0.52 \\
\hline 17 & 0.21 & \multirow{3}{*}{ ( } & 0 & 0.99 & 37 & 0.99 & & 0.57 & 0.99 & 57 & 0.78 & $\mathrm{C}$ & 0.55 & 0.99 \\
\hline 18 & 0.69 & & 0.11 & 0.99 & 38 & 0.24 & $\bar{C}$ & 0 & 0.54 & 58 & 0.99 & \multirow{3}{*}{ NO } & 0.16 & 0.99 \\
\hline 19 & 0.28 & & 0 & 0.99 & 39 & 0.2 & B & 0.02 & 0.38 & 59 & 0.99 & & 0.3 & 0.99 \\
\hline 20 & 0.99 & $\mathrm{~A}$ & 0.38 & 0.99 & 40 & 0.17 & $\bar{C}$ & 0 & 0.99 & 60 & 0.99 & & 0.76 & 0.99 \\
\hline
\end{tabular}

2 